ISSN: 0514-7336

DOI: http://dx.doi.org/10.14201/zephyrus20147383107

\title{
LA NEOLITIZACIÓN DE LA MESETA NORTE Y DE LA ALTA Y MEDIA CUENCA DEL EBRO (ESPAÑA): PREMISAS TEÓRICAS, ANÁLISIS DEL REGISTRO Y PLANTEAMIENTO DE HIPÓTESIS
}

\section{The Neolithisation of the Northern Meseta and High and Middle Ebro Bassin (Spain): Theoretical issues, analysis of the archaeological record and previous hypothesis}

\author{
Ínigo GARCÍA-MARTínEZ DE LAGRÁN
}

Área de Prehistoria. Dpto. de Geografía, Prehistoria y Arqueología. Facultad de Letras. UPV-EHU. Vitoria-Gasteiz. Correo-e:igmtzl@gmail.com

Recepción: 28/10/2013; Revisión: 6/02/2014; Aceptación: 7/04/2014

BIBLID [0514-7336 (2014) LXXIII, enero-junio; 83-107]

RESUMEN: El principal objetivo de este trabajo es el planteamiento de una hipótesis sobre la neolitización de la alta y media cuenca del Ebro y de la Submeseta norte. Para ello, se han precisado una serie de premisas teóricas sobre este proceso histórico, se ha realizado una clasificación particular de los yacimientos implicados sobre la base de estos presupuestos teóricos y la comparación de sus registros -estratigrafía, cronología, materiales, etc.- y finalmente se ha propuesto una definición (pre)histórica de las comunidades que los formaron.

A partir de estos datos se explica la neolitización de este territorio en un marco cronológico concreto -entre el 5700-5600 y el 5400-5300 cal AC- en el que se asumen, como puntos principales, la existencia de comunidades neolíticas colonas 'pioneras', la participación fundamental en este proceso de los grupos mesolíticos locales y el papel esencial de fenómenos de colonización de pídola o infiltración en la extensión del Neolítico por esta área geográfica.

Palabras clave: Neolítico. Mesolítico. Colonización. Aculturación. Contextos arqueológicos. Interior peninsular.

ABSTRACT: The main purpose of this paper is to propose a hypothesis about the Neolithisation of the Upper and Middle Ebro Basin and Northern Meseta (Spain). To achieve this goal, several theoretical topics of this historical process are defined, a classification of the archaeological sites involved in this process is presented, based on these theoretical assumptions and the comparison between their archaeological contexts -stratigraphy, chronology, archaeological materials, etc.-, and a (pre)historical definition of those communities is proposed.

Based on this data, the Neolithisation of this territory is explained within a specific chronological framework -5700-5600 and 5400-5300 cal BC- where it is assumed the existence of Neolithic pioneer communities and the important role in the spread of the Neolithic across this geographical area of both local Mesolithic groups and colonization processes -leapfrog or infiltration types-.

Key words: Neolithic. Mesolithic. Colonisation. Acculturation. Archaeological contexts. Inner Iberia. 


\section{Introducción ${ }^{1}$}

En los últimos años la información disponible para el estudio del proceso de neolitización en la Península Ibérica ha aumentado considerablemente y de manera muy especial en el Valle del Ebro y en la Meseta norte (Iglesias et al., 1996; Alday, 2006; Fernández-Eraso, 2011; Alday et al., 2012; Garrido et al., 2012, etc.). Efectivamente, esta es una de las zonas donde el registro concerniente al Mesolítico final y al Neolítico antiguo $-c$. VI milenio cal $\mathrm{AC}^{2}-$ es más completo, aun así existen todavía determinados periodos -como el Mesolítico en la práctica totalidad de la Meseta- y algunos tipos de yacimientos específicos -como los asentamientos de hábitat al aire libre mesolíticos- de los que carecemos de información.

A pesar de esto último, los datos actuales han permitido proponer una cierta variedad de hipótesis entre las que se pueden citar como ejemplos más recientes las de Alday (2012), Cerrillo (2005), Díaz del Río (2010), Montes y Alday (2012), Rojo et al. (2008b), etc. Sus diferencias, sin grandes extremismos, radican en la distinta definición teórica del concepto de Neolítico, y en la consideración neolítica o mesolítica de determinados yacimientos. En este contexto general, el presente trabajo pretende acotar el marco teórico de la neolitización y ofrecer una clasificación del registro arqueológico implicado -en la misma línea que el realizado por Fernández Eraso (2004) para el País Vasco meridional-. Posteriormente, se expondrá una hipótesis sobre la neolitización de este territorio que se basa y completa

${ }^{1}$ Me gustaría agradecer muy especialmente al Dr. M. A. Rojo Guerra las revisiones y comentarios de este texto. Asimismo, debo dar las gracias a los Dres. A. Alday Ruiz, R. Garrido Pena y E. López-Montalvo y a H. Arcusa por sus comentarios, sugerencias y correcciones. Este trabajo ha sido realizado en el marco del Grupo de Investigación en Prehistoria IT622-13, UPV/EHU y en el laboratorio TRACES-UMR 5608, Univ. Toulouse Le Mirail II.

${ }^{2}$ Salvo que se indique lo contrario, todas las referencias cronológicas serán presentadas calibradas a dos sigma y a. C. La información de las dataciones y sus referencias bibliográficas se encuentran recopiladas en la Fig. 9. varias ideas ya planteadas en trabajos anteriores (Rojo et al., 2008b) ${ }^{3}$.

\section{Teoría y registro}

\subsection{Cuestiones teóricas previas}

La primera cuestión que debemos tener en cuenta al estudiar la neolitización en el continente europeo, y por extensión en la Península Ibérica, es su origen foráneo. Este hecho conlleva una serie de premisas y determinismos que deben ser tenidos en cuenta, tanto para el análisis del registro arqueológico como para el planteamiento de hipótesis:

- Determinismo cronológico: la neolitización de un territorio deberá presentar un cierto desfase cronológico con respecto a las regiones adyacentes, aunque determinados fenómenos de expansión -colonizaciones marítimas, procesos de pídola, etc.puedan dar lugar a situaciones particulares.

- Premisa fundacional: las actividades económicas y el mundo cultural y simbólico del Neolítico son lo suficientemente complejos para que sea necesario un protagonismo poblacional claro en su expansión, lo que no es óbice sino causa de otros fenómenos de difusión cultural y material -circulación de elementos neolíticos por las redes de intercambio mesolíticas, por ejemplo-. Esto conlleva la aparición en el registro de la dualidad cultural (Bernabeu, 1996; Juan-Cabanilles y Martí, 2002, etc.) y de la convivencia de distintos tipos de comunidades y, por lo tanto, de contextos arqueológicos. Esta premisa es especialmente importante en lo relativo al 'Conocimiento fundamental' o Know-How de la tecnología de producción (Rojo et al., 2008b: 324-325). En nuestra opinión, la transferencia de los conocimientos básicos sobre la agricultura y la ganadería exige un contacto personal, estrecho y constante entre el 'maestro' y el 'aprendiz'. Por lo tanto, la

${ }^{3}$ Cf. también García-Martínez de Lagrán, I.: El proceso de neolitización en la Interior Peninsular: la Submeseta Norte y el Alto Valle del Ebro. El análisis de la cerámica como herramienta interpretativa. Tesis doctoral presentada en 2012 en la Univ. de Valladolid (http://uvadoc.uva.es/ handle/10324/1707). 

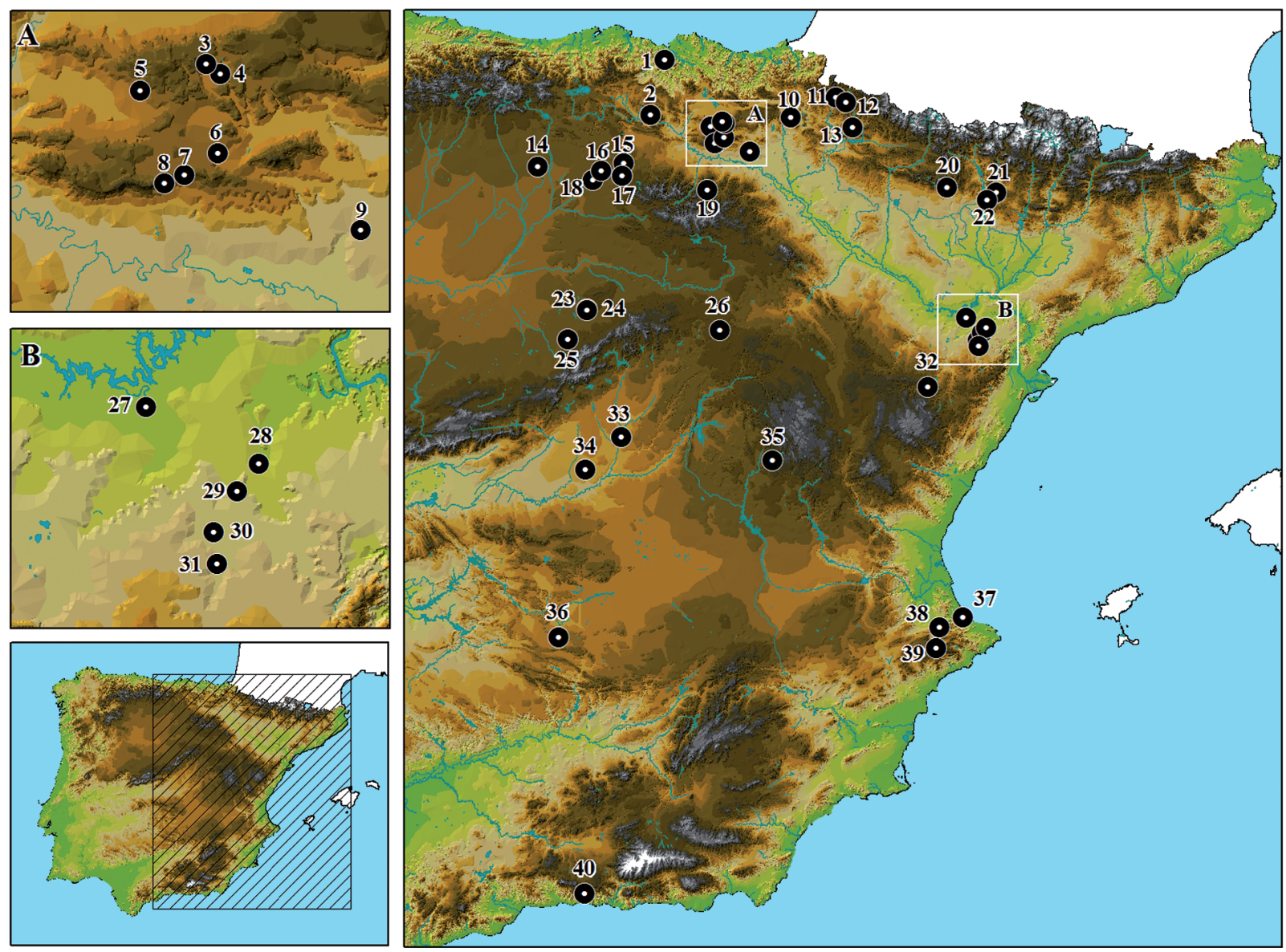

FIG. 1. Yacimientos citados en el texto: 1) Arenaza (Galdames-Vizcaya); 2) El Pópilo (Herrán-Burgos); 3-A) Atxoste (Virgala-Álava); 4-A) Kanpanoste Goikoa (Virgala-Álava); 5-A) Mendandia (Sáseta-Treviño-Burgos); 6-A) La Peña (Marañón-Navarra); 7-A) Peña Larga (Cripán-Álava); 8-A) Los Husos I y II (Elvillar-Álava); 9-A) Los Cascajos (Los Arcos-Navarra); 10) Paternanbidea (Ibero-Navarra); 11) Zatoya (Abaurrea Alta-Navarra); 12) Aizpea (Aribe-Navarra); 13) Padre Areso (Bigüézal-Navarra); 14) La Velilla (Osorno-Palencia); 15) Alto de Rodilla (Monasterio de Rodilla-Burgos); 16) Fuente Celada (Quintanadueñas-Burgos); 17) El Portalón y El Mirador (Ibeas de Juarros-Burgos); 18) Molino de Arriba (Buniel-Burgos); 19) Lóbrega (Torrecilla en Cameros-La Rioja); 20) Chaves (Bastarás-Huesca); 21) Forcas II (Graus-Huesca); 22) Cueva del Moro (Olvena-Huesca); 23) El Espino (Villaseca-Segovia); 24) Abrigo de la Senda del Batán (Burgomillodo-Segovia); 25) La Vaquera (TorreiglesiasSegovia); 26) La Lámpara, La Revilla, El Tormo II y el Abrigo de la Dehesa (Ambrona-Soria); 27-B) Plano del Pulido (Caspe-Zaragoza); 28-B) Costalena (Maella-Zaragoza); 29-B) El Pontet (Maella-Zaragoza); 30-B) El Secans (Mazaleón-Teruel); 31-B) Botiquería dels Moros (Mazaleón-Teruel); 32) Ángel 1 y 2 (Ladruñán-Teruel); 33) El Congosto (Rivas-Vaciamadrid-Madrid); 34) La Paleta (Numancia de La Sagra-Toledo); 35) Verdelpino (Cuenca); 36) Villamayor (Villamayor de Calatrava-Ciudad Real); 37) El Barranquet (Oliva-Valencia); 38) Or (Beniarrés-Alicante); 39) El Mas d'Is (Penàguila-Alicante); 40) Nerja (Nerja-Málaga).

imitación o el mero intercambio verbal y abstracto de ideas no posibilitarían el desarrollo de estas actividades. La aplicación de este concepto tiene como consecuencia la necesidad de que existan grupos o personas plenamente "neolíticas" que entren en contacto -intercambios matrimoniales, convivencia de grupos, etc.- con comunidades locales de cazadores-recolectores.

- Premisa de doble progresividad en los territorios y contextos mesolíticos (Bernabeu, 1996: 49): 
progresividad en la adquisición de los diferentes elementos tecnoeconómicos del Neolítico, que precederán a la progresiva aparición de sistemas plenamente neolíticos.

- Premisa de doble protagonismo: con este concepto intentamos recalcar la necesidad de estudiar a todas las comunidades implicadas en el proceso de neolitización, tanto agricultores y ganaderos como cazadores-recolectores.

- Premisa teórica del concepto de Neolítico (Rojo et al., 2008b: 278 y ss.): esta es una cuestión fundamental a la hora de definir los distintos contextos arqueológicos ya que determinará el carácter y las circunstancias históricas de su formación y contenido material y socioeconómico. En nuestra opinión, el "Neolítico" es, en origen, una importante transformación en las estrategias humanas para la obtención de recursos, esto es, la introducción de la agricultura y la ganadería o, en otras palabras, la producción de alimentos. Pero no sólo es eso, sino mucho más. Esta nueva forma de obtener los alimentos modificó, ya desde el mismo momento de su introducción, la interacción del ser humano con su entorno, las relaciones sociales, los sistemas simbólicos, la cultura material, los patrones de asentamiento, etc.

\subsection{Clasificación e interpretación (pre)histórica de yacimientos}

En base a las premisas, determinismos y conceptos teóricos del punto anterior hemos establecido los siguientes criterios para la clasificación e interpretación de los contextos arqueológicos implicados:

- La presencia/ausencia en el mismo yacimiento de ocupaciones mesolíticas anteriores.

- El tipo de yacimiento y su funcionalidad: abrigos y cuevas explotados como campamentos logísticos y asentamientos al aire libre considerados como lugares de hábitat.

- La importancia cuantitativa y cualitativa de los elementos neolíticos: este punto puede resultar controvertido dada la dificultad para discernir esta "importancia" y el papel representado por la funcionalidad de los propios yacimientos en este aspecto.
- La cronología: debemos advertir que muchas dataciones de los grupos definidos se solapan y, por lo tanto, se desarrollan en un periodo cronológico e histórico más o menos contemporáneo. A pesar de ello hemos mantenido nuestra clasificación con el propósito de identificar las distintas situaciones históricas que, al menos en teoría, forman parte del proceso de neolitización -colonizaciones, interacciones, intercambios, etc.-.

En función de estas variables hemos definido tres grupos de yacimientos -con ciertos matices y comentarios respecto a algunos contextos- que se caracterizan a continuación y cuya localización, junto con otros yacimientos citados en el texto, se recoge en la Fig. 1.

\subsubsection{Grupo $1 .^{\circ}$ de yacimientos: \\ 'Campamentos especializados mesolíticos con elementos neolíticos'}

a) Secuencia estratigráfica y cronología:

En los yacimientos de este grupo se detectan ocupaciones mesolíticas anteriores (Fig. 2) ${ }^{4}$ con respecto a los niveles que analizamos. La cronología de estos contextos es relativamente amplia: desde el nivel III sup de Mendandia: 6240-6010, 6240-5970 y 6120-5980, hasta el nivel 6 de Botiquería: $5060-4790$.

b) Tipo de yacimiento y funcionalidad:

Consideramos a estos abrigos y cuevas como campamentos logísticos destinados a diferentes actividades especializadas. Entre estas destaca la caza pero también son importantes otras labores: tratamiento de pieles, talla de sílex, ahumado de alimentos, etc. Incluso, se han hallado pruebas directas de siega, como señalan las hoces aparecidas en Mendandia II y en Atxoste IIIb (Alday et al., 2012b: 131-136).

\footnotetext{
${ }^{4}$ Varios yacimientos y niveles más podrían ser incluidos en los 3 grupos definidos y en las siguientes tablas, sin embargo, bien por tratarse de contextos con cierta problemática secuencial o estratigráfica -Kanpanoste Goikoa, Verdelpino, Abrigo de la Senda del Batán, El Espino, El Pópilo, por ejemplo-, por falta de datos publicados (Padre Areso) o por dataciones que requieren ciertas matizaciones (Costalena et al., 2000: 298) hemos decidido no incorporar más casos a nuestra relación.
} 


\begin{tabular}{|c|c|c|c|c|c|c|}
\hline \multicolumn{7}{|c|}{ YACIMIENTOS DEL GRUPO $10^{\circ}$} \\
\hline \multicolumn{7}{|c|}{ 'CAMPAMENTOS ESPECIALIZADOS MESOLÍTICOS CON ELEMENTOS NEOLÍTICOS’ } \\
\hline \multirow{3}{*}{ CONTEXTOS } & \multicolumn{2}{|c|}{ ESTRATIGRAFÍA } & \multirow{3}{*}{ 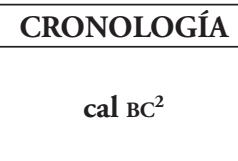 } & \multicolumn{3}{|c|}{ SUBSISTENCIA } \\
\hline & \multirow{2}{*}{$\begin{array}{c}\text { Nivel } \\
\text { suprayacente }^{1}\end{array}$} & \multirow{2}{*}{$\begin{array}{c}\text { Nivel } \\
\text { infrayacente }\end{array}$} & & \multirow{2}{*}{$\begin{array}{c}\text { Flora } \\
\text { Ref. a } \\
\text { domésticos }\end{array}$} & \multicolumn{2}{|c|}{ Fauna-\% } \\
\hline & & & & & Salvaje & Doméstica \\
\hline Ángel 1-8b sup & 8a-Neolítico & 8c-Mesolítico & sin dataciones & $\sin$ datos $^{3}$ & \multicolumn{2}{|c|}{ sin datos } \\
\hline Ángel 2-2a1 & 1-Moderno & 2a2-Mesolítico & sin dataciones & sin datos & \multicolumn{2}{|c|}{ sin datos } \\
\hline Aizpea-III-Ai sup & a-Superficie & $\begin{array}{l}\text { b-parte media } \\
\text { alta (Aizpea II: } \\
\text { Mesolítico) }\end{array}$ & $5476-5221$ & sin evidencias & 100 & 0 \\
\hline Atxoste-IIIb & $\begin{array}{l}\text { II-Neolítico } \\
\text { avanzado }\end{array}$ & IIIb2-Mesolítico & $5316-5020$ & $\begin{array}{l}\text { sin datos, } \\
\text { hoces, un } \\
\text { molino }\end{array}$ & mayoritaria & $\begin{array}{c}\text { restos } \\
\text { domésticos }\end{array}$ \\
\hline Botiquería-6 & $\begin{array}{c}\text { 7-Estéril } \\
\text { (8-Neolítico) }\end{array}$ & $\begin{array}{c}\text { 5-Estéril } \\
\text { (4-Mesolítico) }\end{array}$ & $5194-4796$ & sin evidencias & 100 & 0 \\
\hline Botiquería-8 & Superficie & $\begin{array}{c}\text { 7-Estéril } \\
\text { (6-Neolítico) }\end{array}$ & $5316-5056$ & sin evidencias & 100 & 0 \\
\hline Forcas II-VI & vII-Estéril & v-Neolítico & $5721-5569$ & $\begin{array}{c}\text { sin evidencias, } \\
\text { frags. de } \\
\text { molino }\end{array}$ & \multicolumn{2}{|c|}{ "fauna salvaje" } \\
\hline Forcas II-V & VI-Neolítico & IV-Mesolítico & $5726-5575$ & sin evidencias & \multicolumn{2}{|c|}{ "fauna salvaje" } \\
\hline Mendandia-IIIsup & II-Neolítico & InIinf-Mesolítico & $\begin{array}{l}6235-6019 ; 6239- \\
5916 ; 6207-5983\end{array}$ & sin evidencias & $100^{*}$ & $\begin{array}{c}0 \\
\text { *(un molar de } \\
\text { uro haplotipo } \\
\text { T3) }\end{array}$ \\
\hline Mendandia-II & I-Neolítico & IIIsup-Neolítico & $5621-5371$ & $\begin{array}{c}\text { sin evidencias, } \\
\text { hoces }\end{array}$ & 100 & 0 \\
\hline Mendandia-I & Sup & II-Neolítico & $5479-5331$ & sin evidencias & 100 & 0 \\
\hline La Peńa-d sup & c-Eneolítico & d-Neolítico & sin dataciones & sin evidencias & \multicolumn{2}{|c|}{ sin evidencias } \\
\hline La Peña-d & dsup-Neolítico & $\begin{array}{c}\text { d-parte baja- } \\
\text { mesolítico }\end{array}$ & sin dataciones & sin evidencias & 100 & 0 \\
\hline Pontet-c inf & c sup-Neolítico & $\begin{array}{l}\text { d-Estéril (e: } \\
\text { Mesolítico) }\end{array}$ & sin dataciones & sin datos & \multicolumn{2}{|c|}{ sin datos } \\
\hline Secans-IIa & I & IIb-Mesolítico & sin dataciones & sin evidencias & 100 & 0 \\
\hline Zatoya $I+\mathrm{a} 2.2^{3}$ & superficial & $\begin{array}{c}\text { Ib-b2- } \\
\text { Epipaleolítico }\end{array}$ & sin dataciones & sin evidencias & 100 & 0 \\
\hline
\end{tabular}

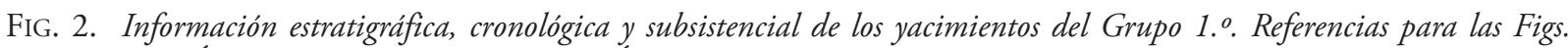
2-3: Ángel 1: Domingo et al., 2010; Ángel 2: Utrilla et al., 2003; Aizpea: Barandiarán y Cava, 2001; Atxoste: A. Alday com. per.; Botiquería: Barandiarán, 1978; El Pontet: Utrilla et al., 2009; Forcas II: Utrilla et al., 2009; Mendandia: Alday, 2006; La Peña: Cava y Beguiristain, 1991-1992; Secans: Ramón, 2006; Utrilla et al., 2009; Zatoya: Barandiarán y Cava, 1989.

1: Se mantiene la definición de los niveles y los comentarios dados por los investigadores de cada yacimiento y así en todos los apartados referidos.

2: Se recogen sólo dataciones sobre muestras de vida corta con una desviación típica \pm inferior a 100 años, en consecuencia, aunque aparezca la frase "sin dataciones", pueden existir otras fechas para algunos contextos.

3: "Sin datos": no se ha publicado información al respecto; "sin evidencias": no existen evidencias de ese elemento en el contexto. 


\begin{tabular}{|c|c|c|c|c|c|}
\hline \multicolumn{6}{|c|}{ YACIMIENTOS DEL GRUPO 1.० } \\
\hline \multicolumn{6}{|c|}{ ‘CAMPAMENTOS ESPECIALIZADOS MESOLÍTICOS CON ELEMENTOS NEOLÍTICOS’ } \\
\hline \multirow{3}{*}{ Contextos } & \multirow{2}{*}{\multicolumn{3}{|c|}{$\begin{array}{c}\text { INDUSTRIA LÍTICA TALLADA } \\
\text { Distribución de instrumentos líticos tallados- } \%{ }^{1}\end{array}$}} & \multirow{3}{*}{ PULIMENTO } & \multirow{3}{*}{ CERÁMICA } \\
\hline & & & & & \\
\hline & 10 & $2^{\circ}$ & $3^{\circ}$ & & \\
\hline Ángel 1-8b sup & $\begin{array}{c}\text { Lascas } \\
\text { retocadas: } \\
33,33\end{array}$ & $\begin{array}{l}\text { Mircoburiles y G: } \\
\qquad 23,33\end{array}$ & $\begin{array}{l}\text { Denticulados: } \\
13,33\end{array}$ & sin datos & 48 fragms. lisos \\
\hline Ángel 2-2a1 & \multicolumn{3}{|c|}{8 geométricos en doble bisel } & sin datos & "un par de restos cerámicos" \\
\hline Aizpea-III-Ai sup & lba: 33,65 & G: 24,04 & D: 11,54 & sin evidencias & 76 fragms. (9 recipientes) \\
\hline A troste Juth & \multirow{2}{*}{\multicolumn{3}{|c|}{$\begin{array}{l}\text { alrededor de medio centenar de segmentos } \\
\text { en doble bisel }\end{array}$}} & \multirow{2}{*}{ restos pulimentados } & 1064 fragms. (14 recipientes) \\
\hline Alxoste-1mD & & & & & Peso: $5216^{2}$ \\
\hline Botiquería-6 & G: 28,24 & MD: 25,88 & D: 16,48 & sin evidencias & 2 fragms. decorados y 9 lisos \\
\hline Botiquería-8 & MD : 39,13 & R y G: 17,4 & P: 8,7 & sin evidencias & 4 fragms. decorados y 7 lisos \\
\hline Forcas II-VI & \multicolumn{3}{|c|}{ "geométricos doble bisel" } & un hacha & impresa e incisa \\
\hline Forcas II-V & \multicolumn{3}{|c|}{ "triángulos abruptos y doble bisel" } & sin datos & cardial, impresa e incisa \\
\hline Mendandia-IIIsup & lba: 20,75 & MD: 18,87 & G: 16,98 & sin evidencias & $\begin{array}{c}337 \text { fragmentos, } 4 \text { recipientes } \\
\text { peso: } 3561\end{array}$ \\
\hline Mendandia-II & G: 28,21 & D: 24,36 & lba: 14,10 & ¿un fragm. de hacha? & $\begin{array}{c}770 \text { fragmentos, } 12 \text { recipientes } \\
\text { peso: } 1760\end{array}$ \\
\hline Mendandia-I & $\mathrm{D}: 29,41$ & MD : 23,52 & $\mathrm{P}: 17,65$ & sin evidencias & 33 fragmentos lisos \\
\hline La Peńa-d sup & \multicolumn{3}{|c|}{3 segmentos ( 2 doble bisel y 1 abrupto) } & sin evidencias & 8 galbos lisos \\
\hline La Peña-d & $\mathrm{G}: 33,84$ & Microburiles: 23,07 & MD: 13,85 & sin evidencias & 35 fragmentos. lisos \\
\hline Pontet-c inf & \multicolumn{3}{|c|}{ "triángulos cocina" } & sin datos & incisa \\
\hline Secans-IIa & $\mathrm{G}: 25$ & MD: 20,31 & $\mathrm{R}: 15,62$ & sin evidencias & $\begin{array}{c}20 \text { fragmentos. (10 de un } \\
\text { único recipiente) }\end{array}$ \\
\hline Zatoya I + a2.2 & Gm: 25,90 & D: 20,66 & G: 16,39 & sin evidencias & 54 fragmentos lisos \\
\hline
\end{tabular}

FIG. 3. Información sobre la industria lítica tallada y pulimentada, y sobre las colecciones cerámicas de los yacimientos del Grupo 1. ${ }^{\circ}$.

1: (igual para todas las tablas): lba: laminitas de borde abatido, MD: muescas y denticulados; G: geométricos; D: diversos; $R$ : raspadores.

2: Peso en g de toda la colección cerámica del nivel o estructura.

Con respecto a la funcionalidad otra cuestión de gran interés es la estacionalidad de este tipo de asentamientos que, a nivel global, se ocupan entre primavera y otoño (Alday, 2006: 440-442, 556563; Alday et al., 2012a, etc.).

c) Territorio:

Para el Mesolítico del valle del Ebro se ha defendido una economía de amplio espectro basada en una explotación planificada y diversificada del territorio (Alday, 2006: 556, 578; Barandiarán y Cava, 2000: 307-308; 2001: 473; Utrilla y Rodanés, 2004: 107; García-Martínez de Lagrán, 2008a). En buena lógica, los elementos neolíticos y las nuevas actividades subsistenciales aparecidos en las ocupaciones superiores de estos campamentos se integrarán en los modos y en los criterios de explotación territorial desarrollados desde el Mesolítico (Alday, 2006; Montes y Alday, 2012; Alday et al., 2012a, etc.). 
d) Materiales arqueológicos:

- Cerámica:

En la mayoría de los yacimientos de este grupo el número de fragmentos cerámicos es escaso y no permiten obtener ninguna conclusión de su estudio, más allá de su presencia (Fig. 3). Únicamente en tres contextos -Mendandia IIIsup y II, y Atxoste IIIb- la cantidad de restos cerámicos es suficientemente relevante para obtener datos significativos.

Recientemente, hemos estudiado en detalle las colecciones cerámicas del territorio analizado (García-Martínez de Lagrán et al., 2011) teando la posibilidad de que existan varios estilos cerámicos en el mismo durante el proceso de neolitización:

- Estilo 1: de mayor antigüedad, definido, precisamente, a partir de las colecciones de Mendandia y que se caracteriza, grosso modo, por composiciones sencillas bajo el borde realizadas con una única técnica decorativa.

- Estilo 2: con una mayor variedad de composiciones, técnicas y un nivel superior de complejidad decorativa respecto al anterior. Se desarrollaría a partir del 5400-5300 y presenta una serie importante de características comunes -temas decorativos, técnicas, instrumentos, etc.- desde el $\mathrm{S}$ de Francia a Andalucía, pero, al mismo tiempo, muestra ciertas peculiaridades regionales. En este Estilo 2 se encuadrarían todas las colecciones cerámicas de los contextos de este grupo $-\mathrm{y}$ de los dos siguientes- excepto los niveles III sup y II de Mendandia, el nivel IV de Peńa Larga y, tal vez, la UE 15 del Abrigo de la Dehesa.

- Industria lítica tallada:

En la Fig. 3 hemos recogido la distribución de los principales instrumentos líticos tallados con una doble finalidad:

1) Corroborar el carácter cinegético de estos yacimientos especializados: efectivamente en estos contextos los grupos mayoritarios suelen ser los geométricos o los bordes abatidos que servirían como puntas de proyectil.

2) Confirmar la presencia de determinadas características que tradicionalmente han sido

${ }^{5}$ Cf. también García-Martínez de Lagrán: op. cit. n. 3. definidas como genuinamente "neolíticas" e indicadoras de una nueva situación o de un cambio tecnotipológico (Cava, 2000: 104-108; 2006: 236-239; Barandiarán y Cava, 2001: 143-145; Utrilla, 2002: 190; Alday, 2006; Montes y Alday, 2012: 54):

- Preponderancia de la talla laminar destinada, de manera significativa, a la obtención de láminas utilizadas en diferentes actividades.

- Utilización del retoque en doble bisel y de tipos segmentiformes. La combinación de estas dos variables presenta ciertas diferencias entre la alta cuenca del Ebro -segmentos en doble bisel casi en exclusividad-, Aragón -convivencia de retoques (abrupto y doble bisel) y de tipos -segmentos, triángulos y trapecios, estos últimos con mayor frecuencia que el primero- $y$ ciertos enclaves pirenaicos -con influencias septentrionales-.

- En estos primeros contextos con elementos neolíticos los elementos de dorso alcanzan su punto máximo para ir decayendo posteriormente.

Una cuestión fundamental para la consideración como neolíticas de estas características líticas es su convivencia con cerámicas y, en algunos casos, con restos pulimentados (Mendandia II, Atxoste IIIb y Forcas II, VI), con láminas utilizadas como hoces -Mendandia II y Atxoste IIIb-, y con restos de animales domésticos -Atxoste IIIb(Figs. 2-3).

- Industria lítica pulimentada:

Cf. Fig. 3.

e) Modo de subsistencia:

Los restos faunísticos de estas ocupaciones son, en su inmensa mayoría, de animales salvajes cazados (Fig. 2). Las características de estas actividades cinegéticas son similares a las definidas en el Mesolítico. Los datos relativos a la recolección son realmente escasos, entre ellos destacan los análisis realizados al esqueleto de Aizpea, que confirman una alimentación básicamente vegetal (Barandiarán y Cava, 2001: 49).

Junto con la caza y la recolección se han detectado pruebas directas e indirectas de domesticación animal y vegetal en algunos contextos: 
- Diferentes restos faunísticos identificados como domésticos:

El análisis provisional del nivel IIIb de Atxoste ha identificado varios restos de animales domésticos que estarían en minoría frente a los salvajes ${ }^{6}$. También se han reconocido 2 o 3 restos de ovicápridos domésticos -sobre un total de 800- en el abrigo de Forcas II (Alday et al., 2012b: 139).

- Presencia de haplotipo T3 en una muestra de un molar de uro en Mendandia III sup:

La presencia de este tipo de haplotipo, relacionado con la domesticación, en fechas de finales del VII y principios del VI milenio (Fig. 2) plantea una serie de cuestiones muy interesantes tanto para el estudio genético de esta especie como para el proceso de neolitización a nivel europeo (Alday et al., 2012b: 139-142). Entre otras posibilidades, estos investigadores interpretan este resto y su contexto como un avance pionero neolítico en el marco de otros yacimientos europeos con restos de agricultura y ganadería en contextos y fechas antiguas (Alday et al., 2012b: 144). Según ellos este "movimiento pionero" no supondría la implantación de la gestión neolítica plenamente desarrollada pero sí su introducción.

- Hoces con lustre de cereal en Mendandia II y Atxoste III (Alday et al., 2012b):

Entre las 86 láminas analizadas en Atxoste y las 42 en Mendandia se han descubierto 3 fragmentos de hoces en el primer abrigo y 1 en el segundo junto con otro elemento con marcas sobre material no leñoso.

- Un molino del nivel IIIb de Atxoste (Alday et al., 2012b: 137-138).

f) Interpretación:

En nuestra opinión estos contextos se definirían como 'campamentos especializados mesolíticos con elementos neolíticos'. Su consideración mesolítica o, en otras palabras, contextos ocupados y explotados por una comunidad de cazadores-recolectores, vendría dada por la continuidad estratigráfica de estos contextos, por la cronología de algunos de ellos y por la escasa representatividad general cuantitativa y cualitativa de los elementos neolíticos de sus registros que pueden ser interpretados como elementos de intercambio. Esta

${ }^{6}$ A. Alday, comunicación personal. interpretación como elementos de "intercambio" "en el seno de una economía todavía epipaleolítica" ya ha sido sugerida por otros investigadores (Utrilla et al., 2009: 168-173).

Asimismo, el tipo de yacimiento, su localización y el registro subsistencial recuperado en estos contextos apuntan claramente a una funcionalidad especializada en diferentes actividades entre las que destaca la caza.

Por último, una parte importante de estos contextos se datan entre el 5700-5600 y el 54005300, periodo en el que, en nuestra opinión, se desarrollaría el proceso de neolitización -Mendandia IIIsup, aún más antiguo, II y I, Forcas II V y VI, Aizpea III-, este dato temporal, unido a las características antes mencionadas, reforzaría la interpretación que proponemos. Existen otros niveles -Atxoste IIIb, Botiquería 6 y 8 - con dataciones más recientes que podrían responder a situaciones históricas particulares que se explicarán más adelante.

\subsubsection{Grupo 2. ${ }^{\circ}$ de yacimientos: 'Neolíticos pioneros'}

a) Secuencia estratigráfica y cronología: Este grupo está formado únicamente por tres contextos de dos yacimientos diferentes: Chaves ib y Ia, y Peña Larga IV. Ambos son lugares de fundación ex novo, sin ocupaciones mesolíticas previas, donde están presentes los elementos neolíticos desde el inicio de su explotación.

Las dataciones de estos contextos son anteriores al 5400-5300 y suponen las fechas más antiguas de niveles neolíticos de la zona estudiada (Figs. 4 y 8 ).

b) Tipo de yacimiento y funcionalidad: La cueva de Chaves puede ser considerada como un asentamiento de hábitat neolítico puesto que como señala Utrilla (2002: 184) esta cavidad representa un magnífico lugar de ocupación permanente con un espacio habitable de $3000 \mathrm{~m}^{2}$ y un curso de agua a $10 \mathrm{~m}$. Por el contrario, el abrigo de Peña Larga es considerado un campamento especializado en la caza y en la guarda de ganado, presentando algunas características propias de un redil (Fernández Eraso, 2011: 125-126). 


\begin{tabular}{|c|c|c|c|c|}
\hline \multicolumn{5}{|c|}{$\begin{array}{l}\text { YACIMIENTOS DEL GRUPO } 2 .^{\circ} \\
\text { 'NEOLÍTICOS PIONEROS' }\end{array}$} \\
\hline \multirow{3}{*}{ CONTEXTOS } & CRONOLOGÍA & \multicolumn{3}{|c|}{ SUBSISTENCIA } \\
\hline & \multirow{2}{*}{ cal BC } & \multirow{2}{*}{$\begin{array}{c}\text { Flora } \\
\text { Ref. a domésticos }\end{array}$} & \multicolumn{2}{|c|}{ Fauna- $\%$} \\
\hline & & & Salvaje & Doméstica \\
\hline \multirow{2}{*}{ Chaves-Ib } & \multirow{2}{*}{$5614-5478 ; 5482-5375$} & \multirow{4}{*}{ "pólenes de cereal" } & N. ${ }^{\circ}$ Restos: 11,9 & N. ${ }^{\circ}$ Restos: 63,21 \\
\hline & & & N.o Inv.: 13,25 & N.o Inv.: 50,70 \\
\hline \multirow{2}{*}{ Chaves-Ia } & \multirow{2}{*}{$5471-5304$} & & N. ${ }^{\circ}$ Restos: 11,31 & N. ${ }^{\circ}$ Restos: 58,74 \\
\hline & & & N.o Inv.: 13 & N. ${ }^{\circ}$ Inv.: 47,96 \\
\hline \multirow{2}{*}{ Peña Larga-IV } & \multirow{2}{*}{$5715-5561$} & \multirow{2}{*}{ sin evidencias } & N. ${ }^{\circ}$ Restos: 35,20 & N. ${ }^{\circ}$ Restos: 64,70 \\
\hline & & & peso: 54,07 & peso: 45,93 \\
\hline
\end{tabular}

FIG. 4. Información cronológica y subsistencial de los yacimientos del Grupo 2. ${ }^{\circ}$. Referencias para las Figs. 4-5: Chaves: Baldellou, 1985, 2011; Cava, 2000; Ramón, 2006; Fauna: Castaños, 2004: 130 (los restos salvajes pertenecen a "ungulados salvajes", el porcentaje restante corresponde a otros mamiferos); Peña Larga: Fernández Eraso, 1997, 2011.

c) Territorio: En contraposición con el primer grupo de yacimientos, parecería lógico asumir que la fundación de 'nuevos' lugares respondería a 'nuevas' pautas y estrategias de explotación del territorio o, por lo menos, a la intención de mejorar e intensificar estas estrategias subsistenciales novedosas, esto es, la agricultura y la ganadería.

d) Materiales arqueológicos:

- Cerámica:

La colección cerámica del nivel IV de Peña Larga (5720-5550) supone una excepción dentro de los yacimientos que estamos analizando ya que no puede ser incluida en ninguno de los dos 'Estilos' mencionados anteriormente. Entre los restos recuperados destaca la presencia de impresiones cardiales realizadas mediante aplicaciones perpendiculares del borde. Esta particularidad y variedad estilística formaría parte de los distintos Estilos que presentan las diferentes comunidades neolíticas pioneras que llegan a la Península Ibérica a partir del 5700-5600 (Bernabeu et al., 2011).

En cambio, los niveles de Chaves presentan una amplia colección de cerámicas con diferentes tipos de recipientes y técnicas decorativas. En el nivel ib la técnica cardial supone el 22,2\% del total de técnicas y en el nivel ib el $8,86 \%$ (Ramón, 2006: 348), el resto de las decoraciones impresas/incisas-acanaladas y plásticas presentan una características similares al 'Estilo 2' ya comentado (García-Martínez de Lagrán et al., 2011).

- Industria lítica tallada:

La distinta presencia porcentual de láminas simples -incluidas en Chaves en los 'Diversos'-, geométricos y 1 ba estaría en relación con la funcionalidad y tipología de los yacimientos. De este modo, y en un sentido amplio, nos encontraríamos, por ejemplo, ante campamentos especializados en la caza donde destacarían los geométricos y las 1 ba empleados como puntas de proyectil y ante lugares de asentamiento con vocación agropecuaria caracterizados por la presencia de láminas simples utilizadas como hoces, entre otros fines.

- Industria lítica pulimentada:

Cf. Fig. 5.

e) Modo de subsistencia:

La mayoritaria presencia de restos de fauna doméstica en ambos yacimientos -con algunos matices porcentuales en Peña Larga- y de pólenes de cereal en Chaves marcaría una diferencia sustancial con los yacimientos del Grupo 1. ${ }^{\circ}$. Al mismo tiempo, estos datos incidirían en el carácter claramente neolítico de estos grupos. 


\begin{tabular}{|c|c|c|c|c|c|}
\hline \multicolumn{6}{|c|}{$\begin{array}{l}\text { YACIMIENTOS DEL GRUPO 2.0 } \\
\text { 'NEOLÍTICOS PIONEROS' }\end{array}$} \\
\hline \multirow[t]{2}{*}{ CONTEXTOS } & \multicolumn{3}{|c|}{$\begin{array}{c}\text { INDUSTRIA LÍTICA TALLADA } \\
\text { Distribución de instrumentos líticos-\% }\end{array}$} & \multirow[t]{2}{*}{ PULIMENTO } & \multirow[t]{2}{*}{ CERÁMICA } \\
\hline & \begin{tabular}{c|}
$1 .^{\circ}$ \\
\end{tabular} & $2 .^{\circ}$ & $3 . .^{\circ}$ & & \\
\hline Chaves - Ib & $\begin{array}{c}\text { "láminas retocadas y/o } \\
\text { con estigmas"1 D: } 53,04\end{array}$ & MD: 15,51 & G: 9,22 & $\begin{array}{c}2 \text { hachas o azadas, } 1 \text { útil } \\
\text { de basalto }\end{array}$ & 3446 fragmentos \\
\hline Chaves - Ia & D: 62,87 & MD: 15,50 & R y p: 4,97 & $\begin{array}{c}1 \text { hachita, } 1 \text { fragm. de } \\
\text { hacha, } 1 \text { fragm. de caliza }\end{array}$ & 3468 fragmentos \\
\hline Peña Larga-IV & G: 30,90 & lba: 16,20 & MD: 14,70 & sin evidencias & $\begin{array}{l}485 \text { fragmentos, } \\
10 \text { recipientes } \\
\text { peso: } 2826\end{array}$ \\
\hline
\end{tabular}

FIG. 5. Información sobre la industria lítica tallada y pulimentada, y sobre las colecciones cerámicas de los yacimientos del Grupo 2. ${ }^{\circ}$.

1: Cava 2000: 117 .

f) Interpretación:

Interpretamos estos contextos como las primeras comunidades neolíticas del territorio estudiado y, de ahí, su apelativo de 'pioneros', en una línea ya manifestada por Baldellou y Utrilla (1999: 226) al definir a Chaves como "un ejemplo paradigmático de una instalación precoz, siendo un centro generador de expansiones coloniales sucesivas". Tres son los argumentos principales para ello: su cronología antigua -anterior al 5400-5300-, su fundación de nueva planta y la importancia de los elementos neolíticos y de la explotación agrícola y ganadera claramente manifestada en sus registros. Asimismo, esta interpretación comporta la aplicación de varios conceptos teóricos vistos en el primer apartado, como la dualidad cultural, la definición propuesta de Neolítico o la transmisión de conocimientos tecnológicos de la agricultura y la ganadería.

\subsubsection{Grupo 3.o de yacimientos - 'Neolíticos consolidados/Neolítico antiguo'}

a) Secuencia estratigráfica y cronología: $\mathrm{Al}$ igual que los 'Neolíticos pioneros', estos yacimientos son fundaciones de nueva planta y en ninguno de ellos se han detectado ocupaciones mesolíticas anteriores. La mayoría de estos yacimientos se desarrollan a partir del 5400-5300 (Fig. 6), con la única excepción de una datación del Hoyo 9 de La Lámpara: KIA-21350: fragmento apendicular de macroungulado quemado: $6871 \pm 33$ BP: 5840-5676. Esta datación supone una anomalía entre la profusa colección de muestras de vida corta datadas del valle de Ambrona, que define la neolitización de esta zona a partir del 5500-5300 y, en ningún caso, en el 5800-5600 (Rojo et al., 2008b: 230-234).

b) Tipo de yacimiento y funcionalidad: A partir de estas dos variables podemos establecer dos conjuntos de yacimientos:

- Asentamientos al aire libre donde pueden aparecer contextos de hábitat y estructuras funerarias: El Congosto, Fuente Celada, La Lámpara, La Revilla, Los Cascajos, Molino de Arriba, Paternanbidea.

Consideramos estos yacimientos como lugares de asentamiento en los que se han descubierto diferentes estructuras, entre ellas, la más común son los hoyos. Estos presentan una amplia tipología en cuanto a medidas, tamańos y funcionalidades. En algunos casos, estos hoyos fueron reutilizados posteriormente como tumbas, por ejemplo, el Hoyo 1 de La Lámpara (Rojo et al., 2008b: 357-375).

En este sentido debemos señalar que algunos de los yacimientos recogidos se definen exclusivamente por la presencia de estructuras funerarias 


\begin{tabular}{|c|c|c|c|c|}
\hline \multicolumn{5}{|c|}{$\begin{array}{l}\text { YACIMIENTOS DEL GRUPO 3.॰ } \\
\text { 'NEOLÍTICO ANTIGUO' }\end{array}$} \\
\hline \multirow{3}{*}{ CONTEXTOS } & \multirow{2}{*}{ CRONOLOGÍA } & \multicolumn{3}{|c|}{ SUBSISTENCIA } \\
\hline & & Flora & \multicolumn{2}{|c|}{ Fauna- $\%^{1}$} \\
\hline & cal BC & Ref. a domésticos & Salvaje & Doméstica \\
\hline $\begin{array}{c}\text { Abrigo de la } \\
\text { Dehesa-UE } 15\end{array}$ & sin dataciones & sin datos & \multicolumn{2}{|c|}{ sin datos } \\
\hline $\begin{array}{l}\text { Alto de Rodilla } \\
\text { Enterramiento }\end{array}$ & $5296-4987^{2}$ & sin datos & \multicolumn{2}{|c|}{ sin evidencias } \\
\hline $\begin{array}{c}\text { Chaves } \\
\text { Enterramiento }\end{array}$ & $5308-5057$ & - & \multicolumn{2}{|c|}{ - } \\
\hline $\begin{array}{l}\text { Cueva del Moro } \\
\text { (Olvena) }^{3}\end{array}$ & sin dataciones & $* 3$ & \multicolumn{2}{|c|}{ *3 } \\
\hline $\begin{array}{l}\text { Cueva Lóbrega- } \\
\text { N. Inferior }\end{array}$ & sin dataciones & sin evidencias & \multicolumn{2}{|c|}{$\begin{array}{c}\text { "vaca y oveja y cabra, además de conejos } \\
\text { o liebres" }\end{array}$} \\
\hline $\begin{array}{l}\text { El Congosto } \\
\text { Enterramiento } \\
\end{array}$ & $5050-4780$ & sin datos & \multicolumn{2}{|c|}{$\sin$ datos } \\
\hline El Mirador-18-245 & $\begin{array}{l}\text { N. 24: } 5208-4942 \\
\text { N. } 23: 5466-5212 \\
\text { N. } 22: 5216-4993 \\
\text { N. 20: } 5210-4856 \\
\text { N. } 18: 5209-4953\end{array}$ & $\begin{array}{l}\text { trigo, cebada, y avena, } \\
\text { linum y vicia }\end{array}$ & \multicolumn{2}{|c|}{$\begin{array}{l}\text { redil, } \\
\text { mayoría de domésticos, } \\
\text { sobre todo ovicápridos }\end{array}$} \\
\hline Fuente Celada & $5208-4961$ & sin datos & \multicolumn{2}{|c|}{$\begin{array}{l}\text { en todo el yacimiento predominan las } 3 \\
\text { especies básicas a las que se suma la caza } \\
\text { de uro, cérvidos y posiblemente caballo }\end{array}$} \\
\hline $\begin{array}{c}\text { La Lámpara } \\
\text { (Enterramiento Hoyo } \\
1 \text { ) }\end{array}$ & $\begin{array}{c}\text { 5470-5323; 5366-5073; 5322-5211 Enterr.: } \\
\text { 5217-4962 y 5047-4848; 5210-4965 }\end{array}$ & $\begin{array}{l}\text { trigo, cebada y } \\
\text { adormidera, } \\
2 \text { molinos }\end{array}$ & $\begin{array}{l}\text { N. }{ }^{\circ} \text { Restos: } 20,9 \\
\text { peso: } 34,8 \\
\text { N.o Inv.: } 26,92\end{array}$ & \begin{tabular}{|c|} 
N. ${ }^{\circ}$ Restos: 76,2 \\
peso: 49 \\
N.o Inv.: 69,23 \\
\end{tabular} \\
\hline La Revilla & $\begin{array}{l}\text { 5470-5233; 5466-5230; 5466-5209; 5320-5216; } \\
\text { 5317-5211; 5321-5058; 5321-5058; 5310-5075; } \\
5316-5056 ; 5302-5070 ; 5309-5011 ; 5290-5052 ; \\
\text { 5219-5034; 5214-5018; 5213-5011; 5220-4851 }\end{array}$ & $\begin{array}{l}\text { trigo, cebada y lino, } \\
1 \text { molino }\end{array}$ & $\begin{array}{l}\text { N. } .^{\circ} \text { Restos: } 12,8 \\
\text { peso: } 6,5 \\
\text { N.o Inv.: } 18,42 \\
\end{array}$ & $\begin{array}{l}\text { N.o Restos: } 78,4 \\
\text { peso: } 59,8 \\
\text { N.o Inv.: } 68,42 \\
\end{array}$ \\
\hline La Vaquera-IA & sin dataciones & \multirow{2}{*}{$\begin{array}{c}\text { cebada, trigo y } \\
\text { leguminosas } \\
\begin{array}{c}1 \text { fragm. de mano de } \\
\text { molino }\end{array} \\
\end{array}$} & $\begin{array}{l}\text { N.o Restos: } 10,96 \\
\text { N.o Inv..: } 18,85\end{array}$ & $\begin{array}{l}\text { N.o Restos: } 42,04 \\
\text { N.o Inv.: } 44,93\end{array}$ \\
\hline La Vaquera-IB & $5482-5322 ; 5213-4834$ & & $\begin{array}{l}\text { N.o Restos: } 9,78 \\
\text { N.o Inv.: } 17,36\end{array}$ & $\begin{array}{l}\text { N.o Restos: } 53,90 \\
\text { N.o Inv.: } 46,29\end{array}$ \\
\hline $\begin{array}{l}\text { Los Cascajos } \\
\text { Enterramientos }\end{array}$ & $\begin{array}{c}\text { 5321-5058; 5291-4846; Enterrs.: 5311-5054; } \\
\text { 5311-4947; 5194-4558 }\end{array}$ & $\begin{array}{c}\text { trigo y cebada } \\
\text { molinos, manos de } \\
\text { molinos y molederas. }\end{array}$ & $\begin{array}{l}\text { "representación } \\
\text { testimonial" }\end{array}$ & \begin{tabular}{|} 
vacuno: $53,7 \% \mathrm{de}$ \\
los restos, $81,5 \% \mathrm{de}$ \\
la carne \\
ovicápridos: $11,9 \%$ \\
de la carne
\end{tabular} \\
\hline Los Husos I-XVI & $5326-5030$ & sin datos & \multicolumn{2}{|c|}{ redil; $\sin$ datos } \\
\hline Los Husos I-XVI & $5225-4854$ & "cereales domésticos" & \multicolumn{2}{|c|}{ redil; sin datos } \\
\hline Los Husos II-VII & $5056-4836$ & sin datos & \multicolumn{2}{|c|}{ redil; sin datos } \\
\hline Los Husos II-IX & $5047-4836$ & sin datos & \multicolumn{2}{|c|}{ redil; sin datos } \\
\hline $\begin{array}{c}\text { Molino de Arriba } \\
\text { Enterramiento }\end{array}$ & c. $5200-5000$ & sin evidencias & \multicolumn{2}{|c|}{ sin evidencias } \\
\hline $\begin{array}{c}\text { Paternanbidea } \\
\text { Enterramiento }\end{array}$ & $5207-4854$ & sin datos & \multicolumn{2}{|c|}{ sin datos } \\
\hline P. del Pulido-cg & sin dataciones & sin datos & \multicolumn{2}{|c|}{ sin datos } \\
\hline
\end{tabular}

FIG. 6. Información cronológica y subsistencial de los yacimientos del Grupo 3. ${ }^{\circ}$. Referencias para las Figs. 6-7: Abrigo de la Dehesa: Rojo et al., 2008a; Alto de Rodilla: Informe inédito de Cronos, 2004 y n. 2 de esta tabla; Cueva del Moro (Olvena): Ramón, 2006; Cueva Lóbrega: Barrios, 2004; El Congosto: Martín, 2007; El Mirador: Allué y Euba, 2008; López et al., 2008; Vergès et al., 2008; Martín et al., 2009; Fuente Celada: Alameda et al., 2011; La Lámpara: Rojo et al., 2008b, García-Martínez de Lagrán, op. cit. n. 3 del texto; La Revilla: Rojo et al., 2008b, García-Martínez de Lagrán, op. cit. n. 3 del texto; La Vaquera: Estremera, 2003, GarcíaMartínez de Lagrán, op. cit. n. 3 del texto; Los Cascajos: García y Sesma, 2008; Los Husos I: Fernández Eraso, 2011; Los Husos II: Fernández Eraso, 2011; Peña Larga: Fernández Eraso, 1997, 2011: Molino de Arriba: Palomino et al., 2011; Paternanbidea: García Gazólaz, 2008; Plano del Pulido: Utrilla et al., 2009.

1: Por norma general, y para todos los contextos, los porcentajes no presentes en la tabla corresponden a restos no clasificables.

2: $6171 \pm 55$ BP datación inédita presentada por. J. Echevarría y C. Alonso en el V Congreso del Neolítico Peninsular (Faro, 2011).

3: Cueva del Moro de Olvena, Tablas 3-4: Fauna: en ambas cámaras se recuperaron restos de animales domésticos y salvajes (Ramón, 2006: 50). Por su parte, Castaños (1996) ha realizado el estudio de la fauna de la Cámara Inferior siendo los domésticos el 76,47\% del total de restos y el 50\% en NMI.

4: Cueva Lóbrega Tablas 3-4: los datos hacen referencia al Nivel Inferior-Neolítico Antiguo y medio (Barrios, 2004).

5: El Mirador: Fauna: niveles 19 y 20 (Martín et al., 2009), en el resto de ocupaciones neoliticas los restos son mayoritariamente de especies domésticas.

6: Estas consideraciones hacen referencia a todo el yacimiento donde también se han excavado estructuras de épocas posteriores.

7: Plano del Pulido: Hemos incluido este yacimiento en este Grupo 3.० ya que el nivel infrayacente al primer nivel Neolitico (Nivel cm) pertenece al Mesolitico de Muescas y Denticulados (Utrilla et al., 2009: 144-145) y, por lo tanto, no puede plantearse la hipótesis de una posible continuidad ocupacional entre el final del Mesolitico y los inicios del Neolitico. 
como Alto de Rodilla, El Congosto, Molino de Arriba o Paternanbidea. Sin embargo, sería plausible asumir que estos últimos responderían a asentamientos al aire libre más amplios, sobre todo si tenemos en cuenta ejemplos como La Lámpara o Los Cascajos.

La presencia de estructuras de habitación no es muy frecuente en estos yacimientos, el caso más destacado es el yacimiento navarro de Los Cascajos. Por último, en algunos de estos asentamientos se han descubierto recintos de diferentes tamaños y características, concretamente en La Revilla (Rojo et al., 2008b: 60-68) y en Los Cascajos ${ }^{7}$.

- Campamentos logísticos con distintas funciones pero en este caso centrados en las actividades productoras: Abrigo de la Dehesa, Cueva Lóbrega, Cueva del Moro, El Mirador, La Vaquera, Los Husos.

En lo que respecta a la explotación ganadera destaca un tipo nuevo de campamento especializado: abrigos y cuevas utilizados como rediles, por ejemplo, en Los Husos (Fernández Eraso y Polo, 2008-2009) o en El Mirador (Vergès et al., 2008).

La estacionalidad de estos contextos presenta diferentes situaciones. En La Vaquera se plantea la hipótesis de un asentamiento estacional de verano, probablemente relacionado con los desplazamientos a corta distancia en busca de pastos y para el aprovisionamiento de distintos recursos que ofrece el piedemonte en el que se localiza (Estremera, 2003: 202-203). En cambio, en El Mirador se considera una posible ocupación de la cavidad durante todo el año, desarrollando un sistema de pastoreo semisedentario (Martín et al., 2009: 89, para los niveles 19-20).

c) Territorio: En nuestra opinión, y al igual que en el caso de los grupos colonos, la ubicación de estos yacimientos y la explotación de su territorio tendrá como principal objetivo la producción agrícola y ganadera. Un buen ejemplo de ello sería la aparición de los rediles o una ocupación más dilatada de algunos yacimientos, determinada y/o posibilitada por el tipo de gestión ganadera, como acabamos de ver.

El registro actual nos muestra que tanto los campamentos especializados como los lugares de

${ }^{7}$ J. Sesma y J. García comunicación personal. hábitat presentan características similares en su localización, por ejemplo, la mayoría de ellos se encuentran cercanos a lugares llanos, amplias vegas y riberas muy aptas tanto para el desarrollo de la agricultura como de la ganadería, por ejemplo, los yacimientos de la Sierra de Atapuerca -El Mirador y Cueva Mayor- o La Vaquera, rodeada de diferentes biotopos (Estremera, 2003: $202-$ 203). En rigor, debemos advertir que estas mismas características se pueden aplicar a varios yacimientos del Grupo 1..$^{\circ}$, como para Atxoste, y su cercanía a las zonas llanas del valle de Arraya, o para Mendandia, a escasa distancia de amplias zonas de pasto explotadas en la actualidad.

En el caso de los lugares de hábitat parecen definirse, aun con más detalle, las características de la ocupación y de la explotación del territorio (García-Martínez de Lagrán, 2008b, 2012):

- Cercanía a humedales, lagunas, zonas endorreicas o de inundación, interfluvios o en la confluencia de varios cursos o fuentes de agua.

- Ubicación en zonas que van desde el fondo del valle hasta el pie de páramo, siempre en áreas llanas o de laderas muy tendidas, con un amplio control visual de las zonas cercanas que son las más aptas para la agricultura y la ganadería.

- Localización en zonas estratégicas de paso y vías naturales de comunicación.

Los mejores exponentes de estas pautas territoriales serían los yacimientos de La Lámpara y La Revilla, junto al inédito de El Tormo II, en el valle de Ambrona (Rojo et al., 2008b) y el asentamiento de Los Cascajos.

d) Materiales arqueológicos:

- Cerámica:

La funcionalidad específica de determinados yacimientos, como los rediles, hace que la presencia de materiales arqueológicos en ellos sea muy reducida -El Mirador, Los Husos, Peńa Larga-. Por el contrario, en otros yacimientos la cultura material es abundante y variada, como en el caso de La Vaquera o en los asentamientos al aire libre: Los Cascajos, La Lámpara o La Revilla, por ejemplo. Las cerámicas de todos estos yacimientos comparten una serie de características que hemos agrupado en un estilo concreto -Estilo 2 (GarcíaMartínez de Lagrán et al., 2011)- característico 


\begin{tabular}{|c|c|c|c|c|c|c|}
\hline \multicolumn{7}{|c|}{ 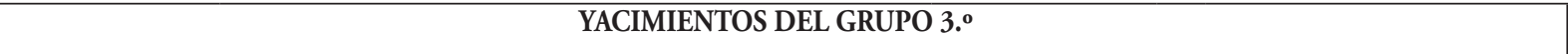 } \\
\hline \multicolumn{7}{|c|}{ 'NEOLÍTICO ANTIGUO' } \\
\hline \multirow{2}{*}{ CONTEXTOS } & \multicolumn{4}{|c|}{$\begin{array}{c}\text { INDUSTRIA LÍTICA TALLADA } \\
\text { Distribución de instrumentos líticos- } \%{ }^{1}\end{array}$} & \multirow[t]{2}{*}{ PULIMENTO } & \multirow{2}{*}{ CERÁMICA } \\
\hline & $1 .^{\circ}$ & 2.0 & & $3 .^{\circ}$ & & \\
\hline $\begin{array}{l}\text { Abrigo de la } \\
\text { Dehesa-UE } 15\end{array}$ & $\begin{array}{l}\text { láminas simples: } \\
70,5\end{array}$ & $\begin{array}{l}\text { G (segmentos): } \\
9,4\end{array}$ & láminas & etocadas: 8,5 & 3 hachas & 32 fragms., 6 recipientes \\
\hline $\begin{array}{l}\text { Alto de Rodilla- } \\
\text { Enterramiento }\end{array}$ & \multicolumn{4}{|c|}{ lascas de sílex sin retoque } & 1 bruñidor & 17 fragmentos (2 decorados) \\
\hline $\begin{array}{l}\text { Cueva Lóbrega- } \\
\text { N. Inferior } \\
\end{array}$ & \multicolumn{4}{|c|}{ mayoritaria presencia de láminas y $\mathrm{MD}$} & sin evidencias & 218 fragmentos \\
\hline $\begin{array}{l}\text { Cueva del Moro } \\
{\text { (Olvena })^{1}}\end{array}$ & D: 38,30 & \multicolumn{2}{|c|}{ G, Bordes abatidos y p: 10,64 } & R: 9,57 & $\begin{array}{l}5 \text { hachas pulimentadas } \\
\text { y } 1 \text { azuela }\end{array}$ & 2641 fragmentos \\
\hline $\begin{array}{l}\text { El Congosto } \\
\text { Enterramiento }\end{array}$ & \multicolumn{4}{|c|}{ sin datos } & sin datos & sin datos \\
\hline El Mirador-18-24 & \multicolumn{4}{|c|}{$\begin{array}{l}\text { gran importancia de la talla laminar, escaso índice de } \\
\text { transformación de los productos y escasa representatividad de } \\
\text { los geométricos }\end{array}$} & \multicolumn{2}{|c|}{$\begin{array}{l}\text { sin datos: "todo ello muy al estilo } \\
\text { de la cerámica documentada en la } \\
\text { región vasco-riojana y cuenca media } \\
\text { del Ebro de mediados y finales del } \\
\text { VI milenio cal BC" }\end{array}$} \\
\hline Fuente Celada & \multicolumn{4}{|c|}{19 restos líticos en las estructuras neolíticas (sin instrumentos) } & sin datos & $\begin{array}{l}\text { cerámicas acanaladas, impresas, } \\
\text { etc. }\end{array}$ \\
\hline La Lámpara & láminas simples: 35,2 & MD: 21 & láminas & tocadas: 16,5 & 7 piezas (1 azuela) & $\begin{array}{c}1347 \text { fragms., } 54 \text { recipientes } \\
\text { peso: } 41119(18897)\end{array}$ \\
\hline La Revilla & láminas simples: 31,9 & MD: 22 & láminas & tocadas: 14,1 & 13 piezas (1 azuela) & $\begin{array}{c}1935 \text { fragms., } 58 \text { recipientes } \\
\text { peso: } 16468 \\
\end{array}$ \\
\hline \multirow{2}{*}{ La Vaquera-IA y IB } & \multirow{2}{*}{ láminas simples: 58,6} & \multirow{2}{*}{ MD: 15} & \multirow{2}{*}{\multicolumn{2}{|c|}{ G y D: 8}} & \multirow{2}{*}{$\begin{array}{l}2 \text { frags. de brazalete y } \\
\text { otros } 4 \text { elementos }\end{array}$} & $\begin{array}{l}\text { IA: } 1175 \text { fragms., } 39 \text { recipientes } \\
\text { peso: } 18197\end{array}$ \\
\hline & & & & & & $\begin{array}{l}\text { IB: } 1890 \text { fragms., } 59 \text { recipientes } \\
\text { peso: } 18284\end{array}$ \\
\hline Los Cascajos & \multicolumn{4}{|c|}{ destacan los cuchillos y las hoces } & hachas y azuelas & $\begin{array}{c}4086 \text { fragms., } 164 \text { recipientes } \\
\text { peso: } 45756\end{array}$ \\
\hline Los Husos I-XVI & \multicolumn{4}{|c|}{ "algunas lascas y un taladro sobre extremo de lámina despejado" } & sin datos & $\begin{array}{l}\text { "el ajuar recuperado es muy } \\
\text { pobre tanto en cantidad como } \\
\text { en calidad" }\end{array}$ \\
\hline Los Husos I-XV & \multicolumn{4}{|c|}{ "lascas y láminas de sílex y un segmento doble bisel" } & sin datos & $\begin{array}{l}\text { "tres fragmentos de vasos } \\
\text { impresos", otros con incisiones } \\
\text { en el labio y lisos }\end{array}$ \\
\hline Los Husos II-VII & \multicolumn{4}{|c|}{ "segmentos de círculo en doble bisel" } & sin evidencias & "muy pobre", cerámicas lisas \\
\hline Los Husos II-IX & \multicolumn{4}{|c|}{$\begin{array}{l}\text { "un segmento de círculo en bisel doble, dos avivados de núcleo, } \\
\text { y cinco lascas" }\end{array}$} & sin datos & "muy pocos restos cerámicos" \\
\hline $\begin{array}{l}\text { Molino de Arriba } \\
\text { Enterramiento }\end{array}$ & \multicolumn{4}{|c|}{ sin evidencias } & sin evidencias & $\begin{array}{l}3 \text { recipientes } \\
\text { peso: } 1172\end{array}$ \\
\hline $\begin{array}{l}\text { Paternanbidea } \\
\text { Enterramiento }\end{array}$ & \multicolumn{4}{|c|}{$\begin{array}{c}\text { Enterramiento 2: } 2 \text { segmentos círculo doble bisel y } 1 \text { lámina } \\
\text { Enterramiento 3: } 4 \text { segmentos círculo doble bisel y } 1 \text { laminita } \\
\text { Enterramiento 4: } 6 \text { segmentos círculo doble bisel y un elemento } \\
\text { de hoz sobre lámina }\end{array}$} & $\begin{array}{l}\text { diferentes tipos de } \\
\text { adornos }\end{array}$ & 1 recipiente \\
\hline P. del Pulido-cg & \multicolumn{4}{|c|}{ "microburiles y geométricos abruptos y de doble bisel" } & sin datos & impresa-cardial \\
\hline
\end{tabular}

FIG. 7. Información sobre la industria lítica tallada y pulimentada, y sobre las colecciones cerámicas de los yacimientos del Grupo 3.․

1: Cueva del Moro de Olvena: Industria lítica tallada: los datos hacen referencia a las cuevas superiores. Cerámica: hemos sumado los fragmentos analizados por Ramón (2006: 49-54) para las diferentes cavidades. 
del interior peninsular y que presenta su máximo desarrollo a partir del 5400-5300, como ya hemos comentado anteriormente. Este estudio, junto con otros también recientes (Ramón, 2006; Alday, $2009)^{8}$, muestran claramente la existencia de una serie de características comunes en este ámbito geográfico y, al mismo tiempo, se detectan particularidades regionales más específicas, que tal vez podrían señalar la presencia de grupos o identidades comunes concretas.

- Industria lítica tallada:

El protagonista destacado de las colecciones líticas de estos yacimientos son las láminas simples, pasando a un lugar secundario los geométricos y las lba. Muchas de estas láminas, simples o retocadas, fueron utilizadas como hoces según los estudios traceológicos (Gibaja, 2008; Gibaja et al., 2012). Desde la perspectiva de la funcionalidad de los yacimientos estos datos podrían indicar un menor interés por la caza, y en algunos casos una dedicación prácticamente exclusiva a las actividades ganaderas -rediles- y agrícolas.

- Industria lítica pulimentada:

Como se puede observar en la Fig. 7, estos yacimientos acogen las mayores colecciones de instrumentos de este tipo de todo el estudio.

e) Modo de subsistencia:

A tenor de los datos recogidos (Figs. 6-7) se puede afirmar que en estos yacimientos el modo de vida es eminentemente productor y que las pruebas tanto directas como indirectas de la existencia de la agricultura y de la ganadería en torno a la mitad del VI milenio son muy numerosas y variadas.

En algunos casos se han propuesto hipótesis más detalladas como en los niveles 19-20 de la Cueva del Mirador. En ellos se considera que la base económica de estos grupos sería la cría de ganado ovicaprino con un pequeño grupo de reses bovinas, y la caza desempeñaría un papel secundario. El ganado ovino se criaría tanto para la producción de carne como para la obtención de productos secundarios, extremo que también podría darse para el ganado vacuno (Martín, Rosell y Vergès, 2009: 89).

${ }^{8}$ Cf. también García-Martínez de Lagrán: op. cit. n. 3. f) Interpretación: Todos los yacimientos de este grupo serían la manifestación arqueológica del final del proceso de neolitización y del inicio del 'Neolítico antiguo'. Esta idea se corrobora tanto por el carácter indudablemente neolítico de todos ellos -fundación ex novo, elementos del package neolítico, agricultura y ganadería, etc.-, como por su proliferación abrumadora en el territorio estudiado y en toda la Península Ibérica a partir del 5400-5300. Es precisamente este carácter 'neolítico consolidado' lo que diferencia a estos contextos de otros anteriores como los 'campamentos especializados mesolíticos con elementos neolíticos'.

\section{Discusión: la neolitización del interior peninsular}

\subsection{Hipótesis sobre la neolitización del interior}

\subsection{1. 'Colonos neolíticos pioneros'}

En nuestra opinión, la neolitización de la Península Ibérica se inicia en torno al 5700-5600 (Fig. 8) cuando aparecen en diferentes puntos de este territorio las primeras comunidades plenamente neolíticas que responden a distintos fenómenos de colonización -marítima, terrestre- con orígenes distintos -S de Francia, Mediterráneo occidental, N de África-. Los contextos arqueológicos que podrían incluirse dentro de este grupo de 'pioneros neolíticos' serían Can Sadurní, El Barranquet, Mas d'Is, Cova d'en Pardo, Nerja, Cabranosa, Padrão (Fig. 1) (Bernabeu et al., 2011; Rojo et al., 2012), cada uno con sus características y particularidades; y en relación directa con el Interior y estudiados en este trabajo: Peńa Larga y Chaves.

\subsubsection{Dualidad cultural. Contactos e intercambios entre grupos distintos}

Todos los contextos citados en el párrafo anterior inaugurarán la dualidad cultural en el territorio peninsular y, por lo tanto, darán inicio a los contactos entre comunidades neolíticas y mesolíticas. 

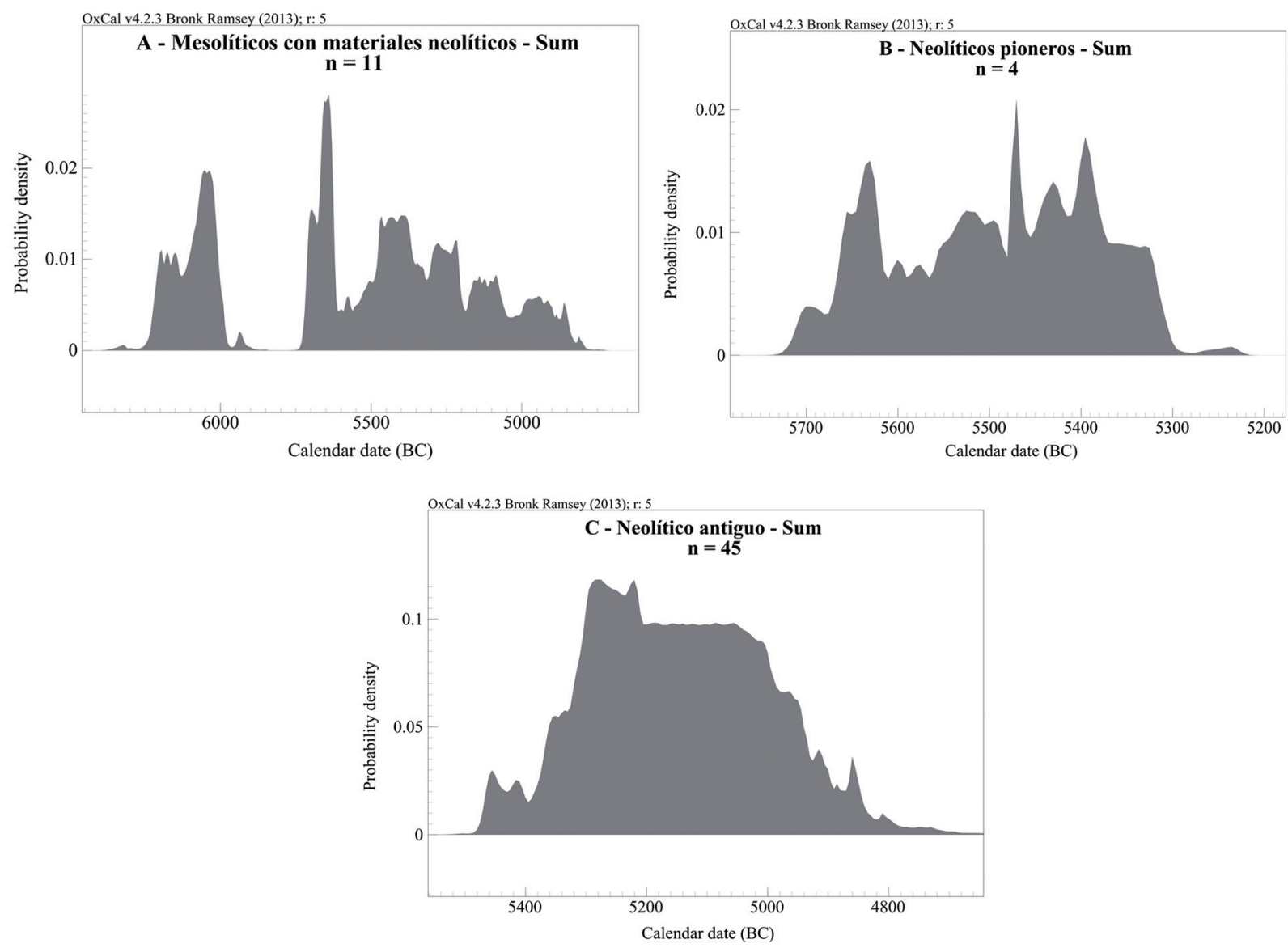

OxCal v4.2.3 Bronk Ramsey (2013); r: 5 IntCal13 atmospheric curve (Reimer et al. 2013)

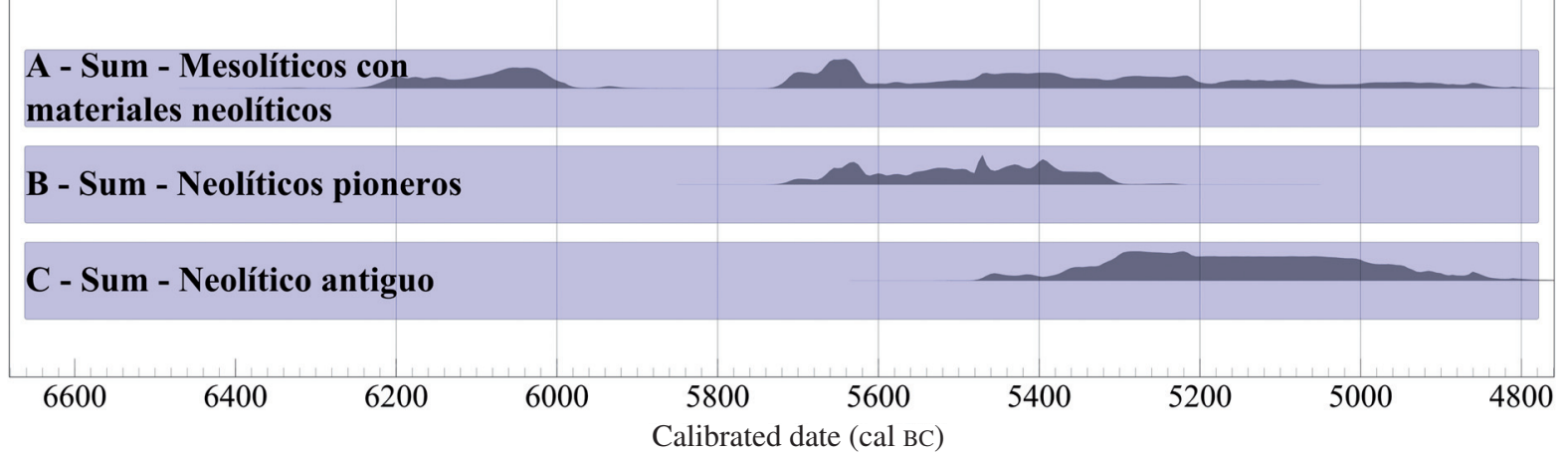

FIG. 8. En la parte superior: gráficos especificos de cada grupo con el n. ${ }^{\circ}$ de dataciones (n) utilizadas y con las probabilidades de densidad; en la inferior: gráfico de la suma de las dataciones citadas en el texto definidas y agrupadas según la interpretación de la hipótesis planteada. 
En consecuencia, y a partir del 5700-5600², deberíamos encontrar entre las comunidades mesolíticas elementos neolíticos fruto de estos intercambios, y viceversa (Fig. 8). En nuestra opinión esta situación histórica se revela en los contextos definidos como 'Campamentos especializados mesolíticos con elementos neolíticos' (Grupo 1. ${ }^{\circ}$ de yacimientos).

\subsubsection{El proceso y el periodo de la neolitización}

El periodo de interacción que acabamos de describir durará hasta $c$. 5400-5300, momento en el que el Neolítico está ya extendido por la práctica totalidad de la Península Ibérica y podemos dar por iniciado el 'Neolítico antiguo'. La prueba de ello sería la gran proliferación de yacimientos plenamente neolíticos que se produce a partir de este momento: 'Neolíticos consolidados' (Grupo 3. ${ }^{\circ}$ de yacimientos, Fig. 8).

Este proceso histórico se caracterizaría por:

- El tipo y significación de los procesos de colonización. No se defiende una colonización masiva ni a gran escala, pero sí una expansión de pídola o infiltración. La característica principal de este tipo de colonización es la existencia de un desplazamiento puntual y direccional, cuyo objetivo sería la ocupación de biotopos concretos: zonas endorreicas, de humedales, con lagunas o de interfluvios que favorezcan el desarrollo de la agricultura y los pastos (Van Andel y Runnels, 1995; Zvelebil, 2000; Rojo et al., 2008b; GarcíaMartínez de Lagrán, 2008b, 2012). Este modelo de colonización tiene como consecuencia una ocupación rala del espacio, pero muy extensa geográficamente desde un punto de vista absoluto,

\footnotetext{
${ }^{9}$ Cabría la posibilidad de que estos intercambios se produjeran anteriormente, como mostraría el nivel IIIsup de Mendandia. En nuestra opinión, y en el estado actual de conocimiento sobre la neolitización peninsular, consideramos esta interpretación como la más plausible para explicar la presencia de elementos neolíticos y otras características en este contexto desde inicios del VI milenio (Figs. 2-3 y 8). Sin embargo, su interpretación es controvertida y, desde luego, debatida (Bernabeu, 2006; Zilhão, 2011; Alday, 2011), y por lo tanto la consideramos como una 'anomalía' dejando las líneas anteriores como una posible interpretación general que deberá ser confirmada en el futuro.
}

lo que posibilitaría nuevos contactos con comunidades mesolíticas en una amplísima área, que, a su vez, favorecería la neolitización rápida del territorio.

En este proceso paulatino de colonización serían muy importantes tanto las primeras comunidades que llegan a la Península Ibérica, que definimos como 'pioneros o comunidades de $1 .{ }^{\text {a }}$ generación', como los siguientes grupos formados por la interacción de éstos con los cazadores-recolectores locales, que formarían 'comunidades de $2 .^{a}, 3 .^{a}, 4 .^{a} \ldots$ generación'. Estas últimas, a su vez, podrían colonizar nuevos territorios dando lugar a nuevos escenarios históricos, dualidades culturales, relaciones, interacciones, transmisión de conocimientos, etc., $y$, finalmente, al inicio del 'Neolítico antiguo' o a las comunidades 'Neolíticas consolidadas' (Grupo 3. ${ }^{\circ}$ de yacimientos) (Rojo et al., 2008b) ${ }^{10}$.

- En esta misma línea, nuestra propuesta asume que estas primeras comunidades del Neolítico presentaban un cierto grado de movilidad, probablemente a medio camino entre una plena sedentarización -que sólo aparecerá en etapas mucho más recientes- y la movilidad de los cazadores-recolectores del Mesolítico (Rojo et al., 2008b).

- La llegada a este territorio de una agricultura y una ganadería desarrolladas y variadas en productos, tecnología y conocimientos (Zapata et al., 2004; Peña y Zapata, 2012). Sin lugar a dudas, esta circunstancia tuvo que favorecer los nuevos asentamientos y un relativo éxito subsistencial y demográfico posterior, plasmado en la proliferación de yacimientos en el registro.

- El papel de los grupos de cazadores-recolectores en este proceso tuvo que ser fundamental para que se produjeran las circunstancias antes referidas. Esta participación es muy difícil de definir en el registro aunque la adquisición de las cerámicas y de otros elementos neolíticos -contextos 'mesolíticos con elementos neolíticos'- sería una prueba, cuando menos, de interacción.

Asimismo, cabría preguntarse las razones por las que estas comunidades abandonaron, en unos pocos siglos, un modo de vida exitoso durante milenios. Al respecto se han planteado algunas

${ }^{10}$ Cf. también García-Martínez de Lagrán: op. cit. n. 3. 
propuestas relacionadas con un posible determinismo ambiental y con el desarrollo socioeconómico de los últimos grupos mesolíticos (Utrilla et al., 2009; García-Martínez de Lagrán, 2008) ${ }^{11}$.

En cualquier caso, esta hipótesis defiende que la neolitización no supondría una elección irremediable para las comunidades indígenas sino que consistiría en una adaptación de todos los ámbitos de estas sociedades mesolíticas -y también de las neolíticas- a un medio cambiante en lo que respecta a su subsistencia, sus relaciones sociales, su demografía, su ocupación del espacio, etc., de su Cultura, en definitiva.

\subsection{Comentarios y cuestiones controvertidas}

\subsubsection{La posible definición neolítica de los contextos definidos como 'mesolíticos con elementos neolíticos'}

Una parte importante de los trabajos relacionados con la neolitización peninsular y del interior en particular considera al Grupo $1 .^{\circ} \mathrm{de}$ yacimientos como neolíticos (por ejemplo: Alday, 2006, 2009, 2012; Barandiarán y Cava, 2000, 2001; Cerrillo, 2005; Díaz del Río, 2010; Montes, 2005: 452; Olària, 2004-2005; etc.). En general y con diferentes matices, estos planteamientos se caracterizan por una idea de progresividad histórica -materializada en la minusvaloración de los procesos colonizadoresy por un protagonismo casi exclusivo de los grupos indígenas durante la neolitización. Como decimos, en este marco, la aparición paulatina de los elementos neolíticos en el registro sería indicadora de esta progresividad y de la implantación gradual de la agricultura y la ganadería. Estas características del registro se explicarían en base a los siguientes puntos fundamentales:

- La continuidad estratigráfica y la cronología: la aparición de los primeros y más antiguos -Mendandia IIIsup y II, Forcas II V y VI- elementos neolíticos en estos contextos sería el primer paso y la primera prueba de la defendida progresividad. Estos grupos "'recibieron, asumieron e interpretaron su propio Neolítico".

${ }^{11}$ Cf. también García-Martínez de Lagrán: op. cit. n. 3.
- La funcionalidad de estos contextos: como se puede ver en la primera parte del trabajo la cantidad de elementos neolíticos en estos niveles es muy reducida, especialmente si se compara con los 'Neolíticos pioneros' y con los 'Neolíticos consolidados'. Para algunos autores esta situación estaría determinada por la funcionalidad específica de estos yacimientos, y no sería el reflejo de intercambios entre comunidades distintas. En otras palabras, es lógico pensar que una comunidad neolítica que ocupa y explota un campamento especializado para la caza -entre otras actividades- no aporte al mismo un gran número de elementos como cerámicas o animales domésticos, no los necesita (Alday, 2006; Alday et al., 2012a y b; Barandiarán y Cava, 2000; Montes y Alday, 2012). Si realmente la aparición escasa y progresiva de estos elementos neolíticos en este tipo de contextos se debiera exclusivamente a su funcionalidad particular, la hipótesis que hemos planteado debería revisarse, al menos en parte.

- La significación de los restos faunísticos: en algunos yacimientos del Grupo $1 .^{\circ}$, especialmente en algunas zonas como en el Bajo Aragón, la presencia de restos de fauna y, por tanto, de domésticos es, en general, muy reducida. En ello, además de factores antrópicos, pueden estar implicados otros como los tipos de suelo que provocan la deficiente conservación de los huesos (Utrilla et al., 2009: 153). Por lo tanto, en algunos casos las definiciones realizadas podrían estar condicionadas por procesos postdeposicionales y enmascarar la realidad histórica de determinados contextos, como por ejemplo Botiquería, Costalena, Plano del Pulido, etc.

- Industria lítica:

Uno de los principales rasgos de neolitización atribuible al Grupo 1. ${ }^{\circ}$ de yacimientos es la transformación de la industria lítica, principalmente las formas segmentiformes, el retoque de doble bisel, etc., todo ello acompañado de la cerámica y otros elementos neolíticos ( $c f$. apartado 2.2.1.d). Por lo tanto, ya no estaríamos hablando únicamente de la aparición de algunos fragmentos cerámicos o de varios restos de animales y plantas domésticos que siempre pueden interpretarse como elementos de intercambio sin gran controversia. Por el contrario, 
100 Íñigo García-Martínez de Lagrán / La neolitización de la Meseta norte y de la alta y media cuenca del Ebro (España)...

\begin{tabular}{|c|c|c|c|c|c|c|}
\hline YACIMIENTO & CONTEXTO & $\begin{array}{l}\text { TIPO DE } \\
\text { MUESTRA }\end{array}$ & $\begin{array}{c}\text { FECHA } \\
\text { BP }\end{array}$ & $\begin{array}{l}\text { CAL BC } \\
(2 \text { sigma })\end{array}$ & REF. LAB. & BIBLIOGRAFÍA \\
\hline Aizpea & III & fauna & $6370 \pm 70$ & $5476-5221$ & BrN-18421 & Barandiarán y Cava, 2001 \\
\hline Alto de Rodilla & & Homo & $6171 \pm 55$ & $5296-4987$ & & $C f$. pie Fig. 6, n. 2 \\
\hline Atxoste & IIIb & fauna & $6220 \pm 60$ & $5316-5020$ & GrA-9789 & Alday, 2012 \\
\hline \multirow[t]{2}{*}{ Botiquería } & 8 & fauna & $6240 \pm 50$ & $5316-5056$ & GrA-13270 & Barandiarán y Cava, 2000 \\
\hline & 6 & fauna & $6040 \pm 50$ & $5194-4796$ & GrA-13268 & Barandiarán y Cava, 2000 \\
\hline \multirow[t]{4}{*}{ Chaves } & $\mathrm{Ib}$ & ovicáprido & $6580 \pm 35$ & $5614-5478$ & GrA-38022 & Baldellou, 2011 \\
\hline & $\mathrm{Ib}$ & ovicáprido & $6470 \pm 25$ & $5482-5375$ & UCIAMS-66317 & Baldellou, 2011 \\
\hline & $\mathrm{Ib}$ & Homo & $6230 \pm 45$ & $5308-5057$ & GrA-26912 & Baldellou, 2011 \\
\hline & Ia & acorn & $6380 \pm 40$ & $5471-5304$ & GrA-28341 & Baldellou, 2011 \\
\hline El Congosto & UE 2242 & Homo & $6015 \pm 40$ & $5041-4788$ & KIA-27582 & Martín, 2007 \\
\hline \multirow[t]{5}{*}{ El Mirador } & MIR 24 & cereal & $6110 \pm 40$ & $5208-4942$ & Beta-220914 & Vergès et al., 2008 \\
\hline & MIR 23 & cereal & $6320 \pm 50$ & $5466-5212$ & Beta-208134 & Vergès et al., 2008 \\
\hline & MIR 22 & cereal & $6150 \pm 40$ & $5216-4993$ & Beta-208133 & Vergès et al., 2008 \\
\hline & MIR 20 & cereal & $6100 \pm 50$ & $5210-4856$ & Beta-197384 & Vergès et al., 2008 \\
\hline & MIR 18 & cereal & $6120 \pm 40$ & $5209-4953$ & Beta-208132 & Vergès et al., 2008 \\
\hline $\begin{array}{c}\text { El Portalón de Cueva } \\
\text { Mayor }\end{array}$ & Nivel 9 & fauna & $6100 \pm 50$ & $5210-4856$ & Beta-222339 & Ortega et al., 2008 \\
\hline \multirow[t]{2}{*}{ Forcas II } & $\mathrm{v}$ & fauna & $6750 \pm 40$ & $5726-5575$ & Beta-247404 & Utrilla et al., 2009 \\
\hline & VI & fauna & $6740 \pm 40$ & $5721-5569$ & Beta-247405 & Utrilla et al., 2009 \\
\hline Fuente Celada & E 62 & Homo & $6120 \pm 30$ & $5208-4961$ & UGRA-7565 & Alameda et al., 2011 \\
\hline \multirow[t]{6}{*}{ La Lámpara } & Ноyo 18 & fauna & $6407 \pm 34$ & $5470-5323$ & KIA-21347 & Rojo et al., 2008b \\
\hline & Hoyo 1 & cereal & $6280 \pm 50$ & $5366-5073$ & UtC-13346 & Rojo et al., 2008b \\
\hline & Hoyo 9 & fauna & $6280 \pm 33$ & $5322-5211$ & KIA -21352 & Rojo et al., 2008b \\
\hline & Hoyo 1 & Homo & $6144 \pm 46$ & $5217-4962$ & KIA -6790 & Rojo et al., 2008b \\
\hline & Hoyo 11 & Fauna & $6125 \pm 33$ & $5210-4965$ & KIA -21348 & Rojo et al., 2008b \\
\hline & Ноуо 1 & Homo & $6055 \pm 34$ & $5047-4848$ & KIA -6789 & Rojo et al., 2008b \\
\hline \multirow[t]{7}{*}{ La Revilla del Campo } & Estructura 14 & fauna & $6365 \pm 36$ & $5470-5233$ & KIA -21358 & Rojo et al., 2008b \\
\hline & Estructura 4 & Ovis & $6355 \pm 30$ & $5466-5230$ & KIA -21356 & Rojo et al., 2008b \\
\hline & Estructura 9 & cereal & $6313 \pm 48$ & $5466-5209$ & UtC-13347 & Rojo et al., 2008b \\
\hline & Estructura 4 & fauna & $6289 \pm 31$ & $5320-5216$ & KIA -21351 & Rojo et al., 2008b \\
\hline & Estructura 14 & fauna & $6271 \pm 31$ & $5317-5211$ & KIA -21357 & Rojo et al., 2008b \\
\hline & Estructura 2 & cereal & $6250 \pm 50$ & $5321-5058$ & UtC-13269 & Rojo et al., 2008b \\
\hline & Estructura 12 & cereal & $6250 \pm 50$ & $5321-5058$ & UtC-13295 & Rojo et al., 2008b \\
\hline
\end{tabular}


Íñigo García-Martínez de Lagrán / La neolitización de la Meseta norte y de la alta y media cuenca del Ebro (España)... 101

\begin{tabular}{|c|c|c|c|c|c|c|}
\hline YACIMIENTO & CONTEXTO & $\begin{array}{l}\text { TIPO DE } \\
\text { MUESTRA }\end{array}$ & $\begin{array}{c}\text { FECHA } \\
\text { BP }\end{array}$ & $\begin{array}{l}\text { CAL BC } \\
\text { (2 sigma) }\end{array}$ & REF. LAB. & BIBLIOGRAFÍA \\
\hline & Estructura 4 & Sus sp. & $6245 \pm 34$ & $5310-5075$ & KIA -21359 & Rojo et al., 2008b \\
\hline & Estructura 16 & cereal & $6240 \pm 50$ & $5316-5056$ & UtC-13294 & Rojo et al., 2008b \\
\hline & Estructura 13 & fauna & $6230 \pm 30$ & $5302-5070$ & KIA -21355 & Rojo et al., 2008b \\
\hline & Estructura 2 & cereal & $6210 \pm 60$ & $5309-5011$ & UtC-13350 & Rojo et al., 2008b \\
\hline & Estructura 2 & fauna & $6202 \pm 31$ & $5290-5052$ & KIA -21346 & Rojo et al., 2008b \\
\hline & Estructura 13 & Ovis & $6177 \pm 31$ & $5219-5034$ & KIA -21354 & Rojo et al., 2008b \\
\hline & Estructura 12 & fauna & $6158 \pm 31$ & 5214-5018 & KIA -21349 & Rojo et al., 2008b \\
\hline & Estructura 12 & Ovis & $6156 \pm 33$ & $5213-5011$ & KIA -21353 & Rojo et al., 2008b \\
\hline & Estructura 4 & cereal & $6120 \pm 60$ & $5220-4851$ & UtC-13348 & Rojo et al., 2008b \\
\hline \multirow[t]{2}{*}{ La Vaquera } & Fase Iв-N.94 & acorn & $6440 \pm 50$ & $5482-5322$ & GrA-9226 & Estremera, 2003 \\
\hline & Fase Iв-N.98 & acorn & $6080 \pm 70$ & $5213-4834$ & GrA-8241 & Estremera, 2003 \\
\hline \multirow[t]{5}{*}{ Los Cascajos } & Estructura 516 & cereal & $6250 \pm 50$ & $5321-5058$ & $\mathrm{Ua}-24427$ & $\begin{array}{c}\text { comunic. personal J. Sesma } \\
\text { y J. García }\end{array}$ \\
\hline & $\begin{array}{c}\text { Inhumación } \\
497\end{array}$ & Homo & $6230 \pm 50$ & $5311-5054$ & Ua-24426 & García y Sesma, 2008 \\
\hline & Estructura 183 & Homo & $6185 \pm 75$ & $5311-4947$ & Ua-16024 & García y Sesma, 2008 \\
\hline & Estructura 214 & Bos & $6125 \pm 80$ & $5291-4846$ & Ua-17795 & $\begin{array}{c}\text { comunic. personal J. Sesma } \\
\text { y J. García }\end{array}$ \\
\hline & Estructura 196 & Homo & $5945 \pm 95$ & $5194-4558$ & Ua-24423 & $\begin{array}{c}\text { comunic. personal J. Sesma } \\
\text { y J. García }\end{array}$ \\
\hline \multirow[t]{2}{*}{ Los Husos I } & xvI & fauna & $6240 \pm 60$ & $5326-5030$ & Beta-161182 & Fernández-Eraso, 2011 \\
\hline & $\mathrm{xv}$ & fauna & $6130 \pm 60$ & $5225-4854$ & Beta-161180 & Fernández-Eraso, 2011 \\
\hline \multirow[t]{2}{*}{ Los Husos II } & VII & fauna & $6050 \pm 40$ & $5056-4836$ & Beta-221640 & Fernández-Eraso, 2011 \\
\hline & IX & fauna & $6040 \pm 40$ & $5047-4836$ & Beta-221642 & Fernández-Eraso, 2011 \\
\hline \multirow[t]{5}{*}{ Mendandia } & Nivel III-sup. & fauna & $7265 \pm 60$ & $6235-6019$ & GrN-19658 & Alday et al., 2012 \\
\hline & Nivel III-sup. & fauna & $7210 \pm 80$ & $6239-5916$ & GrN-19658 & Alday-Ruiz, 2006 \\
\hline & Nivel III-sup. & fauna & $7180 \pm 45$ & $6207-5983$ & GrN-22742 & Alday-Ruiz, 2006 \\
\hline & Nivel II & fauna & $6540 \pm 70$ & $5621-5371$ & GrN-22741 & Alday-Ruiz, 2006 \\
\hline & Nivel I & fauna & $6440 \pm 40$ & $5479-5331$ & GrN-22740 & Alday-Ruiz, 2006 \\
\hline Paternanbidea & $\begin{array}{l}\text { Fosa1 Individ. } \\
\quad 2\end{array}$ & Homo & $6090 \pm 40$ & $5207-4854$ & GrA-13673 & García Gazólaz, 2008 \\
\hline Peńa Larga & IV & ovicáprido & $6720 \pm 40$ & $5715-5561$ & Beta-242783 & Fernández-Eraso, 2011 \\
\hline
\end{tabular}

FIG. 9. Dataciones citadas en el texto y representadas en la Fig. 8; la mayoría de ellas están recogidas en Rojo et al., 2012: 581-603. Calibración: OxCal v4.2.3. 
estaríamos ante una transformación profunda y de gran envergadura en un elemento tan significativo y trascendental como los instrumentos líticos dedicados a la caza y a otras actividades.

Si consideramos esta idea, estaríamos admitiendo una enorme y trascendental capacidad transformadora, o bien el intercambio de productos y/o ideas por las redes sociales mesolíticas, o bien unas comunidades neolíticas pioneras anteriores al 5700-5600 de las que, al menos en la actualidad, no tenemos evidencia arqueológica alguna.

Como hipótesis alternativa podríamos considerar que la aparición de segmentos y de doble bisel es un paso más de la evolución del geometrismo mesolítico en particular y de su tecnología lítica en general, eso sí, coincidente con la aparición de ciertos elementos neolíticos (Arias, 2007: 58; Guilaine y Manen, 2007: 30-32). En esta línea, estas características específicas podrían considerarse como una mejora tecnológica en la elaboración de proyectiles para la caza. Atendiendo a la cronología y a la clasificación de los yacimientos donde aparecen -Mendandia IIIsup y II, o Forcas II V y VI, por ejemplo-, podrían interpretarse como una invención mesolítica que se encontraría por intercambio en los contextos neolíticos pioneros.

También podríamos incluir las láminas -sin retoques o con retoques simples o de uso-. En este caso su versatilidad tiene como consecuencia que puedan utilizarse para múltiples tareas, tanto en un medio depredador como productor.

\subsubsection{La evolución de los 'mesolíticos con} elementos neolíticos': el final del Mesolítico y la neolitización

Una situación realmente interesante de la evolución de los yacimientos del Grupo $1 .^{\circ}$ es lo que sucede cuando aparecen los primeros elementos neolíticos: en la mayoría de los casos se produce una reducción en la intensidad de su ocupación - descenso del número total de restos e instrumentos líticos y de fauna-, rompiendo una tendencia de incremento progresivo a lo largo de todo el Mesolítico (García-Martínez de Lagrán, 2008a: 55). La respuesta en el contexto interpretativo de los investigadores citados anteriormente (cf. apartado 3.2.1) parece sencilla: la producción agrícola y ganadera se va imponiendo progresivamente, relegando a las actividades depredadoras a un puesto secundario. Este sería otro punto a favor de una progresividad en el desarrollo del Neolítico en el seno de las comunidades locales.

Sin embargo podrían plantearse otras posibilidades, bien es cierto que lejos aún de ser comprobadas fehacientemente. Por ejemplo, podríamos considerar un cambio en el modo subsistencial al final del Mesolítico orientado a una mayor explotación de los recursos vegetales por lo que se abandonarían estos altos especializados fundamentalmente en la caza o se explotarían con menor intensidad. Otra posibilidad sería considerar un determinismo ambiental - ¿efectos a medio y largo plazo del Evento 8.2?- que produjera una crisis medioambiental y subsistencial que se manifiesta en un descenso poblacional por lo que se disminuye el número y la intensidad de explotación de los cazaderos de estas comunidades, o bien, una combinación de ambas.

\subsubsection{El marco cronológico de los 'campamentos mesolíticos con elementos neolíticos'}

Sin lugar a dudas, el Grupo 1. de yacimientos es el más problemático en cuanto a su definición. Como ya hemos visto, esto se debe a distintos problemas arqueológicos, tafonómicos, postdeposicionales, etc., y, de manera particular, a la cronología que muestran. De los 16 contextos de este grupo sólo 9 disponen de dataciones y estas definen un marco cronológico amplio, como ya hemos comentado. En consecuencia, uno de los principales problemas interpretativos de la hipótesis que hemos planteado es la explicación y definición de algunos contextos de este Grupo $1 .^{\circ}$ que presentan cronologías más allá del 5300 e incluso del 5000 (Figs. 2 y 8), cuando se supone que la neolitización ya habría concluido. Una primera respuesta podría ser que estos contextos responderían a actividades especializadas de comunidades neolíticas pero, muy posiblemente, no sólo de la caza, sino también de la ganadería y de la agricultura. Si este fuera el caso, estos contextos deberían incluirse en el Grupo 3. ${ }^{\circ}$ de yacimientos. 
Otra posibilidad distinta es que estos niveles sean el testimonio de los últimos grupos de cazadores-recolectores o bien de comunidades mesolíticas en transición hacia el modo de vida neolítico, en este caso su definición como 'mesolíticos con elementos neolíticos' sería correcta. Estas siguen cazando en yacimientos con una larga solera mesolítica, pero ya habrían iniciado su transformación, como indican los restos domésticos y de actividades productoras. Esto supondría alargar en el tiempo el proceso de neolitización propiamente dicho.

\section{Conclusiones}

Como hemos podido comprobar en la sección anterior, son muchos los puntos por debatir y aclarar que quedan sobre la neolitización del Interior Peninsular y varias las propuestas que los recogen y desarrollan. En nuestra opinión, y en aras de la objetividad, no podemos desechar ninguna de ellas. Sin embargo, pensamos que la que aquí presentamos es convincente en lo concerniente a la relación entre la interpretación del registro y el contexto teórico de la neolitización como proceso histórico, especialmente en los siguientes puntos:

- La existencia de una dualidad cultural: en base al análisis del registro disponible parece clara la existencia de diferentes tipos de contextos/comunidades, mesolíticas y neolíticas, en un periodo cronológico concreto.

- Únicamente en el marco de esta interpretación dual podrían desarrollarse dos cuestiones fundamentales de la neolitización como proceso histórico: por un lado, el concepto de progresividad en la adquisición de 'rasgos' y tecnología neolíticos y, por otro, las condiciones especiales para ello, es decir, un contacto directo entre aprendiz y maestro en su transmisión.

- En nuestra opinión, la relativa rapidez del proceso se debe a la combinación de diferentes causas, como el tipo de colonización de pídola o infiltración, o, y tal vez más importante, a sus protagonistas. Defendemos que la aparición del Neolítico en la Península Ibérica está ligada a comunidades colonas neolíticas (pioneros o comunidades de $1 .^{\mathrm{a}}$ generación), pero su posterior desarrollo y expansión encuentra su mejor explicación en la interacción entre éstas y los grupos locales (comunidades de 2. ${ }^{\mathrm{a}}, 3 \mathrm{.}^{\mathrm{a}} \ldots$ generación).

- Por último, esta explicación nos parece más acertada a la hora de integrar la neolitización peninsular en el marco general continental, a tenor de los datos cronológicos y arqueológicos de otras zonas europeas.

Dicho todo esto nos parecen muy acertadas las palabras de A. Sherrat (2005: 145) para concluir este trabajo: "Podemos ponernos de acuerdo sobre los posibles escenarios existentes entonces, pero no así sobre cuál de ellos se dio en cada zona. El registro arqueológico, como suele suceder, no nos ayuda a escoger entre ellos el más adecuado para cada área. En este contexto resulta vital contar con interpretaciones enfrentadas, ya que el surgimiento de un consenso indicaría una falta de imaginación y casi seguro la adopción de una reconstrucción parcial o completamente falsa. Que continúe el debate: no dejemos que el polvo se asiente".

Y, también, estas otras de T. S. Khun (2012[1962]: 263): “Todas las teorías históricamente significativas han concordado con los hechos, aunque sólo más o menos. No hay una respuesta más precisa a la pregunta acerca de si una teoría concreta encaja, o de cómo encaja de bien, con los hechos. [...] No obstante, esta manera de exponer las cosas hace que la tarea de elegir entre distintos paradigmas parezca más fácil y más familiar de lo que en realidad es”.

\section{Bibliografía}

Alameda, M. C.; Carmona, E.; Pascual, S.; MarTínez, G. y DíEz, C. (2011): "El campo de hoyos calcolítico de Fuente Celada (Burgos): datos preliminares y perspectivas", Complutum, 22 (1), pp. 47-69.

Alday, A. (2006): El legado arqueológico de Mendandia: Los modos de vida de los últimos cazadores en la Prehistoria de Treviño. Memorias Arqueología en Castilla y León, 15. Valladolid: JCyL.

Alday, A. (2009) (coord.): Reflejos del Neolitico ibérico: la cerámica boquique: caracteres, cronología y contexto. Barcelona: edit. Edar. 
Alday, A. (2011): "New data for the study of the Neolithic in the Interior of the Iberian Peninsula. Comments on J. Zilhão's interpretation of the Mendandia site", Munibe, 62, pp. 197-205.

Alday, A. (2012): "The Neolithic in the Iberian Peninsula: an explanation from the perspective of the participation of Mesolithic communities", Zephyrus, LXIX, pp. 75-94.

Alday, A.; Carretero, J. M.; Anderung, C. y Götherström, A. (2012a): "Uros, genética, indígenas y colonos. A propósito de la neolitización de Europa", Veleia, 29, pp. 335-358.

Alday, A.; Castaños, P. y Perales, U. (2012b): "Quand ils ne vivaient pas seulement de la chasse: preuves de domestication ancienne dans le gisements néolithiques d'Atxoste et de Mendandia (Pays Basque)", L'Anthropologie, 116, pp. 127-147. http://dx.doi.org/10.1016/j.anthro.2012.03.007

Alday, A.; Montes, L. y Baldellou, V. (2012): "El Neolítico en la Cuenca del Ebro". En Rojo, M. A.; GARrido, R. y GarcíA, I.: El Neolitico en la Península Ibérica y su contexto europeo. Madrid: ed. Cátedra, pp. 463-505.

Allué, E. y EuBA, I. (2008): “Los datos antracológicos de la secuencia neolítica de El Mirador (Atapuerca, Burgos): un estudio sobre el medio vegetal y la explotación de las especies vegetales leñosas". En Hernández, M. S.; Soler, J. A. y López, J. A. (eds.): IV Congreso del Neolítico peninsular (Alicante, 2006). Alicante: MARQ, t. I, pp. 345-352.

Arias, P. (2007): "Neighbours but diverse: social change in north-west Iberia during the transition from the Mesolithic to de Neolithic (5500-4000 cal BC)". En Whittle, A. y Cummings, V. (eds.): Going Over: The Mesolithic-Neolithic transition in North-West Europe. Proceedings of the British Academy, 144. Oxford: OuP, pp. 53-71.

BAldellou, V. (1985): "Comentario a los materiales neolíticos”, Bolskan, 1, pp. 67-94.

Baldellou, V. (2011): "La Cueva de Chaves (Bastarás-Casbas, Huesca)”. En Bernabeu, J.; Rojo, M. A. y Molina, L. (coords.): Las primeras producciones cerámicas. El VI milenio cal A. C. en la Península Ibérica. Saguntum Extra, 12. Valencia, pp. 141-144.

Baldellou, V. y Utrilla, P. (1999): "Le Néolithique en Aragon". En Le Néolithique du Nord-Ouest Méditerraneén. XXIV CPF (Carcassonne, 1994). Carcassonne, pp. 225-237.

BARANDiARÁN, I. (1978): “El abrigo de la Botiquería dels Moros, Mazaleón (Teruel). Excavaciones arqueológicas de 1974", Cuadernos de Prehistoria y Arqueología Castellonense, 5, pp. 49-138.
BARANDiARÁn, I. y CAVA, A. (1989): El yacimiento prehistórico de Zatoya (Navarra). Evolución ambiental y cultural a fines del Tardiglaciar y en la primera mitad del Holoceno. Trabajos de Arqueología Navarra, 8. Pamplona.

BARANDiARÁn, I. y CAVA, A. (2000): “A propósito de unas fechas del Bajo Aragón: reflexiones sobre el Mesolítico y el Neolítico en la Cuenca del Ebro", SPAL, 9, pp. 293-326.

BarandiarÁn, I. y CAVA, A. (2001): Cazadores-Recolectores en el Pirineo navarro. El sitio de Aizpea entre 8000 y el 6000 años antes de ahora. Veleia, Serie Mayor, 10. Vitoria-Gasteiz: UPV/EUH.

BArrios, I. (2004): El yacimiento de Cueva Lóbrega (Torrecilla en Cameros, La Rioja). Una visión acerca del Neolitico y la Edad del Bronce en el área occidental del Sistema Ibérico. Historia-Arqueología, 15. Logrońo: IER.

BernabeU, J. (1996): "Indigenismo y Migracionismo. Aspectos de la neolitización en la fachada oriental de la Península Ibérica", Trabajos de Prehistoria, 53 (2), pp. 37-54.

http://dx.doi.org/10.3989/tp.1996.v53.i2.391

BernabeU, J. (2006): "Una visión actual sobre el origen y difusión del Neolítico en la Península Ibérica. Ca. 5600-5000 cal a. C.”. En GARcíA, O. y AurA, J. E. (coords.): El Abric de La Falguera (Alcoi, Alacant). 8.000 años de ocupación humana en la cabecera del río de Alcoi, Alicante: Diput. Prov. de Alicante-Ayto. de Alcoy-CAM, pp. 189-211.

Bernabeu, J.; Rojo, M. A. y Molina, L1. (coords.) (2011): Las primeras producciones cerámicas. El VI milenio cal A. C. en la Península Ibérica. Saguntum Extra 12. Valencia.

Castaños, P. (1996): "Estudio de la fauna de la cámara inferior de la cueva del Moro (Olvena, Huesca)", Bolskan, 13, pp. 139-141.

CAstaños, P. (2004): "Estudio arqueozoológico de los macromamíferos del Neolítico de la Cueva de Chaves (Huesca)", Saldvie, 4, pp. 125-171.

CAvA, A. (2000): "La industria lítica del Neolítico de Chaves (Huesca)”, Salduie, 1, pp. 77-164.

CAva, A. (2006): "Las industrias líticas retocadas de Mendandia”. En Alday, A. (2006): El legado arqueológico de Mendandia: Los modos de vida de los últimos cazadores en la Prehistoria de Treviño. Memorias Arqueología en Castilla y León, 15. Valladolid: JCyL, pp. 147-244.

Cava, A. y Beguiristain, M. A. (1991-1992): “El yacimiento prehistórico del abrigo de La Peña (Marañón, Navarra)", Trabajos de Arqueología Navarra, 10, pp. 69-135. 
CERRILlO, E. (2005): Los primeros grupos neolíticos de la Cuenca extremeña del Tajo. BAR, Int. S., 1393. Oxford: Archaeopress.

DíAz Del Río, P. (2010): “The Neolithic Argonauts of the Western Mediterranean and Other Underdetermined Hypotheses of Colonial Encounters". En Bolender, D. J. (ed.): Eventful Archaeologies. New Approaches to Social Transformation in the Archaeological Record. Monograph Series IEMA. New York: SUNY Press, pp. 88-99.

Domingo, R.; Martínez, M. y Utrilla, P. (2010): "Una nueva ocupación neolítica en el río Guadalope: la campańa de 2009 en el abrigo de Ángel 2", Salduie, 10, pp. 225-235.

Estremera, M. ${ }^{a}$ S. (2003): Primeros agricultores y ganaderos en la Meseta Norte: el Neolítico de la Cueva de La Vaquera (Torreiglesias, Segovia). Arqueología en Castilla y León, Memorias 11, Valladolid: JCyL.

FERNÁNDEZ ERASO, J. (1997): Excavaciones en el abrigo de Peña Larga (Cripán, Álava). Memorias de yacimientos alaveses, 4. Vitoria: Diput. Foral de Álava.

FernÁndez ERAso, J. (2004): "El Neolítico inicial en el País Vasco meridional. Datos recientes", Kobie, Serie Anejos, 6 (vol. 1), pp. 181-190.

FERNÁNDEZ ERASO, J. (2011): "Las cerámicas neolíticas de La Rioja alavesa en su contexto. Los casos de Peña Larga y Los Husos I y II". En Bernabeu, J.; Rojo, M. A. y MolinA, Ll. (coords.): Las primeras producciones cerámicas. El VI milenio cal AC en la Peninsula Ibérica. Saguntum Extra, 12. Valencia, pp. 117-129.

Fernández Eraso, J. y Polo, A. (2008-2009): “Establos en abrigos bajo roca de la Prehistoria Reciente: su formación, caracterización y proceso de estudio. Los casos de Los Husos y San Cristobal", Krei, 10, pp. 39-51.

García Gazólaz, J. (2008): "Los enterramientos neolíticos del yacimiento de Paternanbidea (Ibero)". En La tierra te sea leve. Arqueología de la muerte en Navarra. Pamplona: Gobierno de Navarra, pp. 59-65.

García Gazólaz, J. y Sesma, J. (2008): “Enterramientos en el poblado neolítico de Los Cascajos (Los Arcos)". En La tierra te sea leve. Arqueología de la muerte en Navarra. Pamplona: Gobierno de Navarra, pp. 52-58.

García-Martínez de LAGRÁN, I. (2008a): "La cuestión de la complejidad socioeconómica en las comunidades de cazadores-recolectores mesolíticas en la Alta y Media cuenca del Ebro", Trabajos de Prehistoria, 65 (2), pp. 49-71.
García-Martínez de Lagrán, I. (2008b): "Los humedales y las zonas endorreicas en los modelos de colonización del interior peninsular durante el Neolítico Antiguo: el Valle de Ambrona y el Valle del Ebro". En Dialogando con la cultura material. I Jornadas de Jóvenes en Investigación Arqueológica (Madrid, 2008). Madrid: UCM, pp. 155-162.

García-Martínez de Lagrán, I.; Garrido, R.; Rojo, M. A.; Alday, A.; García Gazólaz, J. y Sesma, J. (2011): "Cerámicas, estilo y neolitización: estudio comparativo de algunos ejemplos de la Meseta norte y Alto valle del Ebro". En BerNABeU, J.; Rojo, M. A. y Molina, Ll. (coords.): Las primeras producciones cerámicas. El VI milenio cal AC en la Peninsula Ibérica. Sagumtum Extra, 12. Valencia, pp. 83-104.

GARrido, R.; Rojo, M. A.; García, I. y TeJEDOR, C. (2012): "Cuenca del Duero". En RoJo, A.; GarrIDO, R. y García-Martínez DE LAGRÁn, I. (coords.): El Neolítico en la Peninsula Ibérica y su contexto europeo. Madrid: ed. Cátedra pp. 463-505.

GibajA, J. F. (2008): "La función del utillaje lítico documentado en los yacimientos neolíticos de La Revilla del Campo y La Lámpara (Ambrona, Soria)". En Rojo, M. A.; Kunst, M.; Garrido, R.; García-Martínez de LAGRÁN, I. y MorÁn, G.: Paisajes de la Memoria: asentamientos del Neolitico antiguo en el Valle de Ambrona. Valladolid: Univ. de Valladolid y DAI, pp. 451-492.

Gibaja, J. F.; Estremera M. ${ }^{a}$ S.; IbÁÑez, J. J. y Perales, U. (2012): "Instrumentos líticos tallados del asentamiento neolítico de La Vaquera (Segovia) empleados en actividades agrícolas", Zephyrus, LXX, pp. 33-47.

Guilaine, J. y Manen, C. (2007): "From Mesolithic to Early Neolithic in the western Mediterranean". En Whittle, A. y Cummings, V. (eds.): Going Over: The Mesolithic-Neolithic transition in NorthWest Europe. Proceedings of the British Academy, 144. Oxford: OuP, pp. 21-51.

Hernández, M. S.; Soler, J. A. y LóPez, J. A. (eds.) (2008): IV Congreso del Neolítico peninsular (alicante, 2006). Alicante: MARQ, t. 1.

Iglesias, J. C.; Rojo, M. A. y Álvarez, V. (1996): "Estado de la cuestión sobre el Neolítico en la Submeseta Norte". En I Congrés del Neolitic a la Península Ibèrica. Rubricatum, 1 (2). Gavá: ed. Bellaterra, pp. 721-734.

Juan-Cabanilles, J. y Martí, B. (2002): "Poblamiento y procesos culturales en la Península Ibérica del VII al V milenio a. C. (8000-5500 BP). Una cartografía de la neolitización”. En BADAL, E.; BERnabeu, J. y Martí, B. (eds.): El Paisaje en el 
106 Iñigo García-Martínez de Lagrán / La neolitización de la Meseta norte y de la alta y media cuenca del Ebro (España)...

Neolítico mediterráneo. Saguntum, Extra-5. Valencia, pp. 45-87.

KuHN, T. S. (2012): La estructura de las revoluciones cientificas. México D.F.: FCE.

López García, J. M.; Cuenca, G. y Rosell, J. (2008): "Resultados del estudio de mircovertebrados del Neolítico de la cueva de El Mirador (Ibeas de Juarros, Sierra de Atapuerca, Burgos)". En HerNÁNDEZ, M. S.; Soler, J. A. y LóPEZ, J. A. (eds.): Actas IV Congreso del Neolítico peninsular (Alicante, 2006). Alicante: MARQ, t. I, pp. 228-344.

Martín, P.; Rosell, J. y Vergès, J. M. ${ }^{a}$ (2009): “La gestión de los recursos faunísticos durante el Neolítico en la Sierra de Atapuerca (Burgos): los niveles 19 y 20 de la Cueva del Mirador", Trabajos de Prehistoria, 66 (2), pp. 77-92.

http://dx.doi.org/10.3989/tp.2009.09024

Martín Bañón, A. (2007): "Yacimiento de El Congosto (Rivas-Vaciamadrid). La fase neolítica". En Actas II Jornadas de Patrimonio Arqueológico en la Comunidad de Madrid. Madrid: Comunidad de Madrid, pp. 201-205.

Montes, L. (2005): "El Neolítico en Aragón. Últimos datos". En Arias, P.; Ontañón, R. y GarcíaMoncó, C. (eds.): Actas III Congreso del Neolitico en la Península Ibérica. Monografías del IIIP, 1. Santander, pp. 445-454.

Montes, L. y Alday A. (2012): "Enredados en la malla neolítica de la cuenca del río Ebro. Redes, continuidades y cambios". En Congrés Internacional Xarxes al Neolitic. Rubricatum, 5. Gavá, pp. 51-60.

OlÀrIA, C. (2004-2005): "El tránsito hacia las economías de producción de las últimas tribus cazadorasrecolectoras del Mediterráneo peninsular. Una reflexión acerca de la validez de las tesis difusionistas frente a las evolucionistas", Quaderns de Prehistòria i Arqueologia de Castelló, 24, pp. 43-60.

Ortega, A. I.; Juez, L.; CArretero, J. M.; Ortega, M. C.; Arsuaga, J. L. y Pérez-González, A. (2008): "El Neolítico en la nueva secuencia estratigráfica del yacimiento del Portalón de Cueva Mayor (Sierra de Atapuerca, Burgos)". En HeRNÁNDEZ, M. S.; Soler, J. A. y LÓPEZ, J. A. (eds.): IV Congreso del Neolitico peninsular (Alicante, 2006). Alicante: MARQ, t. 1, pp. 221-229.

Palomino, A. L.; Rojo, M.; Garrido, R.; GarcíaMartínez de Lagrán, I.; Alday, A.; García, J. y Sesma, J. (2011): "El Molino de Arriba (Buniel, Burgos)". En Bernabeu, J.; Rojo, M. A. y MoliNA, Ll. (coords.): Las primeras producciones cerámicas. El VI milenio cal AC en la Península Ibérica. Saguntum Extra, 12. Valencia, pp. 113-116.
PeÑA, L. y ZaPATA, L. (2012): "Las transformaciones económicas del Neolítico en la Península Ibérica: la agricultura”. En ROJO, M. A.; GARRIDO, R. y GARCía-MARTínez de LAGRÁn, I. (coords.): El Neolítico en la Peninsula Ibérica y su contexto europeo. Madrid: ed. Cátedra, pp. 95-106.

Ramón, N. (2006): La cerámica del Neolítico Antiguo en Aragón. Caesaraugusta, 77. Zaragoza: Inst. Fernando el Católico.

Rodanés, J. M. y PicAzo, J. V. (2005): El proceso de implantación y desarrollo de las comunidades agrarias en el valle medio del Ebro. Monografías Arqueológicas, 40. Zaragoza: Univ. de Zaragoza.

Rojo, M. A.; Garrido, R. y García-Martínez de LAGRÁN, I. (2008a): "La ocupación del Neolítico antiguo en el Abrigo de Carlos Álvarez/La Dehesa (Miño de Medinaceli, Soria)". En Hernández, M. S.; Soler, J. A. y López, J. A. (eds.): Actas IV Congreso del Neolítico peninsular (Alicante, 2006). Alicante: MARQ, pp. 246-251.

Rojo, M. A.; Kunst, M.; Garrido, R.; GarcíaMartínez de Lagrán, I. y MorÁn, G. (2008b): Paisajes de la Memoria: asentamientos del Neolítico antiguo en el Valle de Ambrona. Valladolid: Univ. de Valladolid y DAI.

Rojo, M. A.; Garrido, R. y García-Martínez DE Lagrán, I. (coords.) (2012): El Neolítico en la Peninsula Ibérica y su contexto europeo. Madrid: ed. Cátedra.

Rubio, I. (1989): "El Neolítico peninsular. Una interpretación de los datos arqueológicos", Cuadernos de Prehistoria y Arqueología de la Univ. Autónoma de Madrid, 16, pp. 11-41.

Sherrat, A. (2005): "Settling the Neolithic: a digestif”. En Bailey, D.; Whittle, A. y Cummings, V. (eds.): (Un)settling the Neolithic. Oxford: Oxbow Books, pp. 140-146.

Utrilla, P. (2002): "Epipaleolíticos y neolíticos del Valle del Ebro". En El paisaje en el Neolítico mediterráneo. Saguntum Extra, 5, pp. 179-208.

Utrilla, P.; Domingo, R. y Martínez, M. (2003): "La campaña del año 2002 en el Arenal de Fonseca (Ladrunán, Teruel)”, Salduie, 3, pp. 310-311.

Utrilla, P. y Mazo, C. (1997): "La transición del Tardiglaciar al Holoceno en el Alto Aragón: los abrigos de las Forcas (Graus, Huesca)". En Actas II Congreso de Arqueología Peninsular. Tomo I- Paleolitico y Epipaleolítico, pp. 349-365.

Utrilla, P. y Montes, L. (coords.) (2009): El Mesolitico geométrico en la Península Ibérica. Monografías Arqueológicas, 44. Zaragoza: Univ. de Zaragoza.

Utrilla, P.; Montes, L.; Mazo, C.; Martínez BeA, M. y Domingo, R. (2009): "El Mesolítico geométrico 
en Aragón”. En Utrilla, P. y Montes, L. (coords.): El Mesolitico geométrico en la Peninsula Ibérica. Monografías Arqueológicas, 44. Zaragoza: Univ. de Zaragoza, pp. 131-190.

Utrilla, P. y RodANÉs, J. M. (2004): El Abrigo de Los Baños (Ariño, Teruel). Un asentamiento epipaleolítico en el valle del Río Martín. Monografías Arqueológicas, 9. Zaragoza: Univ. de Zaragoza.

VAn Andel, T. H. y RunNels, C. N. (1995): "The earliest farmers in Europe", Antiquity, 69, pp. 481-500.

Vergès, J. M.; Allué, E.; Angelucci, D. E.; BurJachs, F.; CARnacho, A.; Cebriá, A.; Expósito, I.; Fontanals, M.; Moral, S.; Rodríguez, A. y VAQUero, M. (2008): "Los niveles neolíticos de la Cueva de El Mirador (Sierra de Atapuerca, Burgos): nuevos datos sobre la implantación y el desarrollo de la economía agropecuraria en la Submeseta norte". En Hernández, M. S.; Soler, J. A. y LóPez, J. A. (eds.): IV Congreso del Neolítico peninsular (Alicante, 2006). Alicante: MARQ, t. I, pp. 418-427.
Vicent, J. M. (1997): “The Island Filter Model revised". En Balmouth, A.; Gilman, A. y Prados L. (eds.): Encounters and transformations. The archaeology of Iberian in transition. Sheffield University Press, pp.1-13.

Zapata, L.; Peña, L.; Pérez Jordá, G. y Stika, H. P. (2004): "Early neolithic agriculture in the Iberian Peninsula", Journal of World Prehistory, 18 (4), pp. 283-325. http://dx.doi.org/10.1007/s10963-004-5621-4

ZILhão, J. (2011): “Time is on my side...”. En HADJIKOUMIS, A.; Robinson, E. y VINER, S. (eds.): The dynamics of Neolithisation in Europe. Studies in honour of Andrew Sherratt. Oxford: Oxbow Books, pp. 46-65.

ZveLEBIL, M. (2000): "The social context of the agricultural transition in Europe". En RENFrew, C. y BOYLE, K. (eds.): Archaeogenetics: DNA and the populations prehistory of Europe. Monographs MIAR. Cambridge, pp. 57-79. 